\section{ENTERRAMIENTOS $Y$ DIFERENCIACION SOCIAL I. EL REGISTRO FUNERARIO DEL YACIMIENTO DE LA EDAD DEL BRONCE DE PEÑALOSA (BAÑOS DE LA ENCINA, JAEN)}

\author{
BURIALS AND SOCIAL HIERARCHISA- \\ TION I. THE FUNERARY RECORD \\ FROM THE BRONZE AGE SITE OF \\ PEÑALOSA (BAÑOS DE LA ENCINA, \\ JAEN)
}

FRANCISCO CONTRERAS CORTÉS (*) JUAN ANTONIO CÁMARA SERRANO (*) RAFAEL LIZCANO PRESTEL (*)

CRISTÓBAL PÉREZ BAREAS (*)

BEATRIZ ROBLEDO SANZ (**)

GONZALO TRANCHO GALLO (**)

\section{RESUMEN}

Se presentan en este artículo los resultados del análisis del registro funerario del yacimiento de la Edad del Bronce de Peñalosa (Baños de la Encina, Jaén) y su relación con la organización del espacio al interior del mismo poblado. Se presta especial atención a la situación de las tumbas bajo las viviendas, a los ajuares en ellas depositados y a las características antropológicas de los esqueletos, que se intentan relacionar con las diferencias documentadas entre las viviendas del poblado.

\footnotetext{
ABSTRACT

The results of the analysis of the funerary record and its relation to the spatial organization of the Bronze Age

(*) Departamento de Prehistoria y Arqueología. Facultad de Filosofía y Letras. Universidad de Granada. 18071 Granada. España

(**) Departamento de Biología Animal I. Facultad de Biología. Universidad Complutense Madrid. Madrid. España

El artículo fue remitido en su versión final el 30-IV-95.
}

settlement of Peñalosa (Baños de la Encina, Jaén) are presented in this paper. Differences between habitation units have been related to differences in tomb location under the houses, in grave goods and in the anthropological characteristics of the human beings buried there.

Palabras clave: Edad del Bronce. Alto Guadalquivir. Paleoantropología. Metalurgia. Jerarquización Social. Urbanismo.

Key words: Bronze Age. Alto Guadalquivir. Palaeoanthropology. Metallurgy. Social Hierarchisation. Urbanism.

\section{PEÑALOSA: UN YACIMIENTO DE LA EDAD DEL BRONCE EN EL ALTO GUADALQUIVIR}

El yacimiento de la Edad del Bronce de Peñalosa se sitúa en una región geográfica que tiene como protagonista al río Guadalquivir (Fig. 1), auténtico eje este-oeste que atraviesa por entero la provincia de Jaén, creando un amplio 
valle que se cierra al este por las Sierras de Cazorla y Segura y, por el contrario, se abre hacia occidente por las campiñas de Córdoba, hacia la Baja Andalucía (Hernández Pacheco, 1926; Cabanas, 1953; Corchado Soriano, 1963; Higueras Arnal, 1961). Tanto al norte como al sur está delimitado por dos barreras montañosas: Sierra Morena y el Subbético, franqueadas, sin embargo, por una serie de pasos y afluentes del Guadalquivir que abren esta zona tanto a la Meseta como al Sureste de la Península Ibérica.

Esta zona geográfica, en la que se enmarca Peñalosa, presenta un estado de la investigación bastante precario hasta mediados de los 80 cuando se inicia el Proyecto de Investigación "Análisis histórico de las comunidades de la Edad del Bronce en la Depresión Linares-Bailén y estribaciones meridionales de Sierra Morena" (1), aunque eran muchas las noticias recogidas y los yacimientos detectados, pasando para la Edad del Bronce de los cincuenta. Por ello, vemos como lo que podríamos considerar como una primera fase del análisis regional, es decir, la definición de las entidades arqueológicas en el tiempo y en el espacio aún no había sido concluida en el Alto Guadalquivir. Ello ha hecho que apenas se haya avanzado en el estudio sistemático del registro arqueológico y que la mayor parte de las síntesis construidas hasta el momento (Lull, 1983; Ruiz et alii, 1986) estén muy limitadas por la falta de datos secuenciales y cronológicos.

Peñalosa se haya ubicado en la margen derecha del río Rumblar, dentro del término municipal de Baños de la Encina, siendo sus coordenadas geográficas $38^{\circ} 10^{\prime} 19^{\prime \prime}$ de latitud norte y $3^{\circ}$ 47' 37 ' de longitud oeste. El poblado se asienta sobre un espolón de pizarra en forma de lengua, con pendientes pronunciadas, estando enmarcado por el arroyo Salsipuedes y el propio río Rumblar (Lám. I). Se alza, por tanto, sobre dicho río, cuyo valle está inundado actualmente por las aguas del embalse del Rumblar. Este yacimiento ha tenido y tiene un gran papel en la valoración cultural de la Edad del Bronce del mediodía peninsular, al haber sido considerado como el poblado más septentrional de la expansión de la Cultura del Argar en su búsqueda de mineral de cobre (Valiente, 1980; Lull, 1983).

(1) Este proyecto de Investigación ha sido dirigido en su primera fase por F. Contreras, F. Nocete y M. Sánchez y financiado por la Dirección General de Bienes Culturales de la Consejería de Cultura de la Junta de Andalucía.

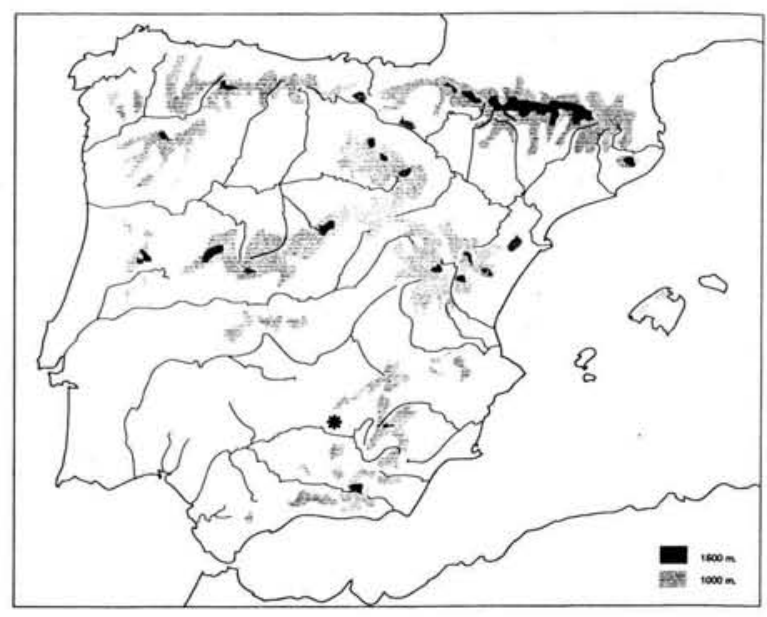

Fig. 1. Localización del poblado de la Edad del Bronce de Peñalosa (Baños de la Encina, Jaén).

El yacimiento fue excavado a principios de los años sesenta por R. García Serrano (Arribas, 1973; Molina et alii, 1979; Contreras et alii, 1987b; Contreras, 1995). Sin embargo, la documentación de dicha actuación, centrada en la parte superior del poblado, nunca fue publicada, desconociéndose en la actualidad los resultados de la misma. Las primeras noticias publicadas al respecto y de las que se derivaron las adscripciones culturales con que se dotó a este yacimiento son las referentes a una colección de materiales obtenidos del expolio (Muñoz Cobo, 1976). Los restos constructivos que actualmente son visibles en la superficie del cerro son el fruto de cuatro campañas de excavación realizadas en los años 1986, 1987, 1989 y 1991 por un equipo de investigadores del Departamento de Prehistoria y Arqueología de la Universidad de Granada dirigido por F. Contreras Cortés, F. Nocete Calvo y M. Sánchez Ruiz.

Peñalosa se ha convertido tras estas campañas de excavación en un yacimiento modélico para el estudio y contrastación del mundo de la Edad del Bronce en el Alto Guadalquivir. Ello se debe no sólo a su localización en la zona minera de Sierra Morena, sino también al buen estado de conservación de su registro arqueológico, a pesar de la erosión postdeposicional que ha sufrido por el efecto del embalsamiento del agua, presentando una última fase del poblado marcada por el abandono repentino del mismo. Esto se manifiesta en una buena conservación no sólo de los complejos estructurales, sino 


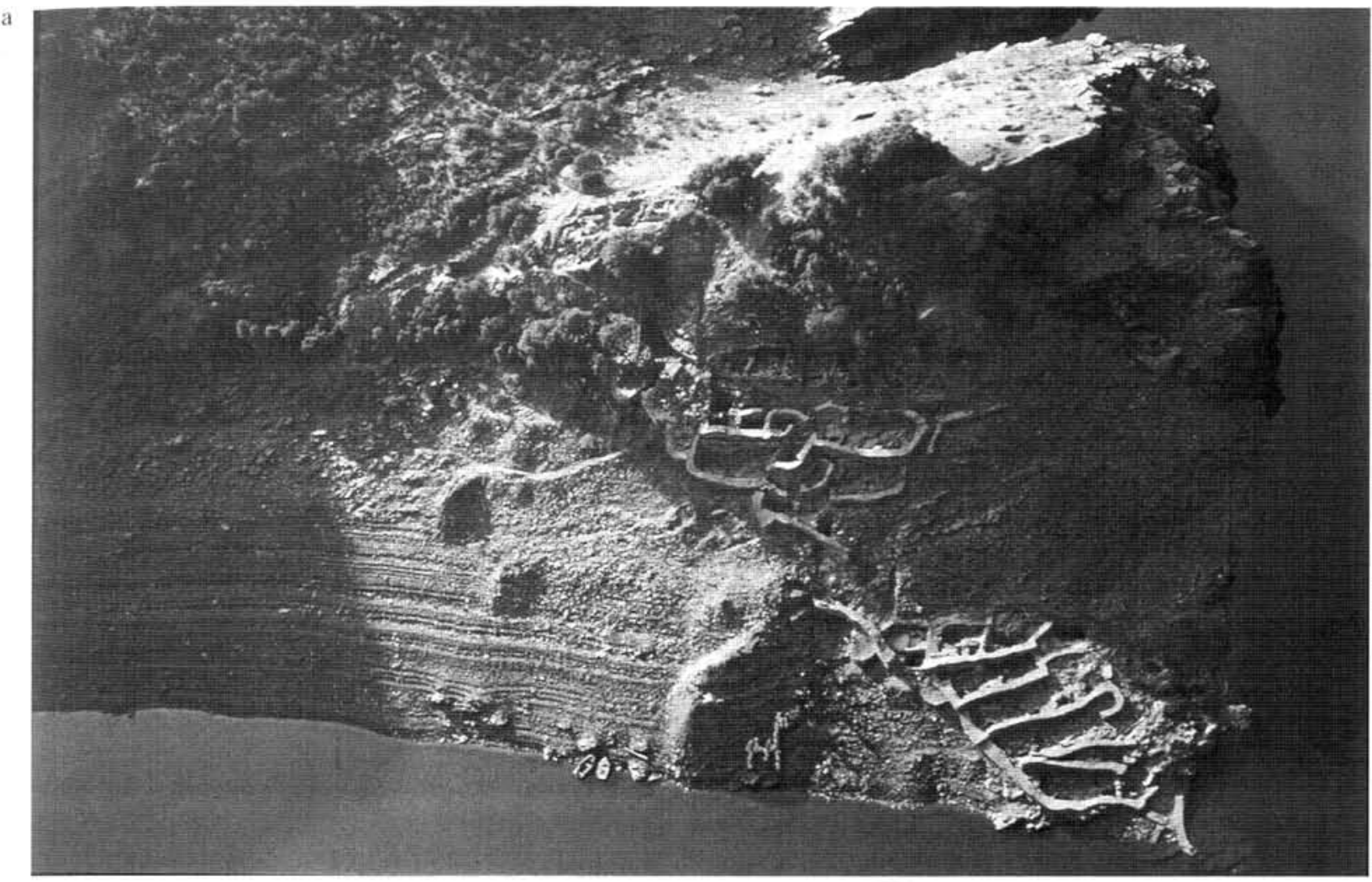

b

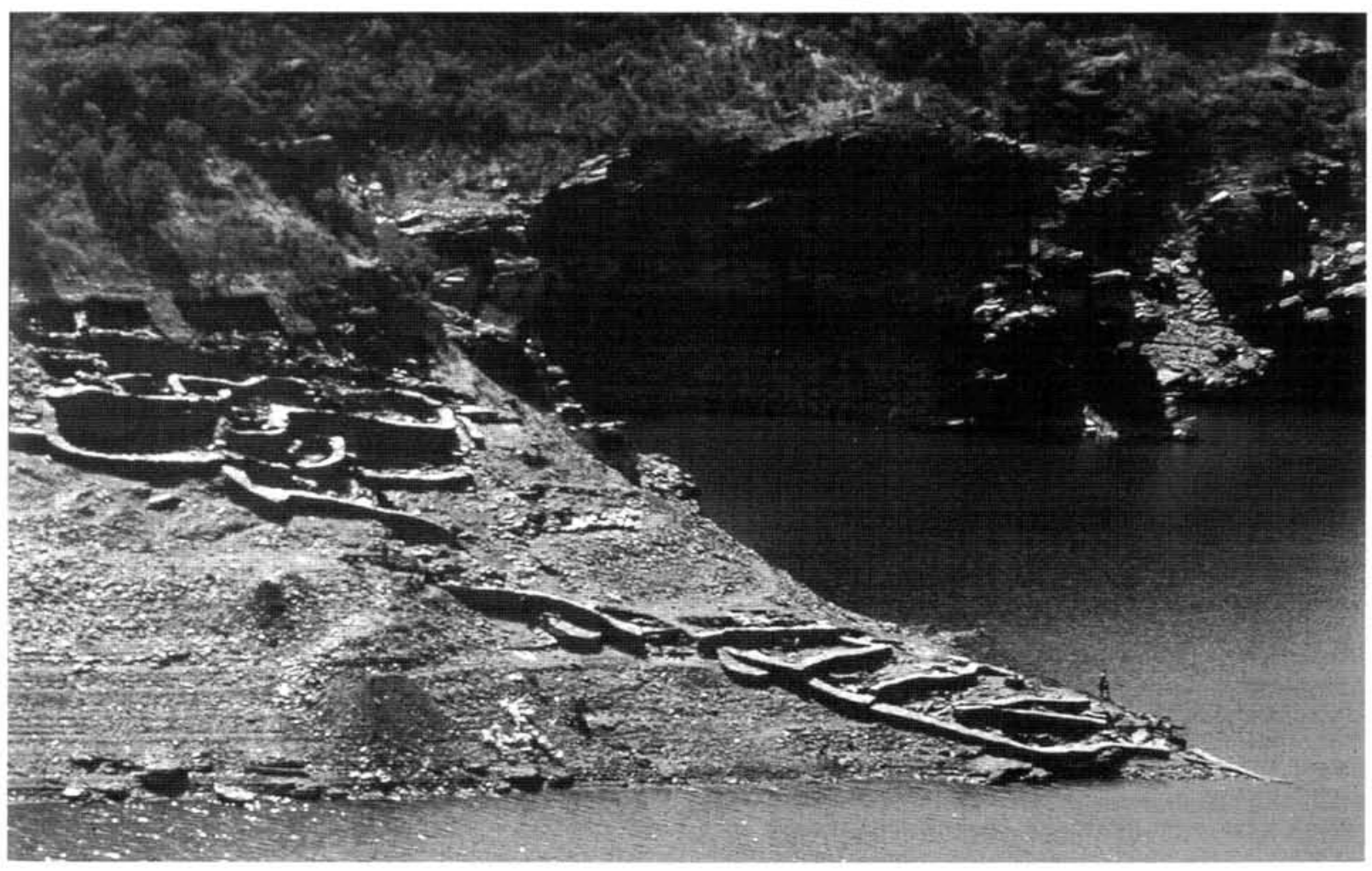

Lám. 1. Peñalosa: vista área (a) y frontal (b). 
también de la cultura material asociada a ellos. Esta situación ha propiciado el desarrollo de un detallado análisis microespacial que nos ha conducido a la interpretación funcional del espacio en el asentamiento, factor clave para la reconstrucción socioeconómica de estas comunidades.

Se ha podido definir la existencia de al menos dos grandes fases constructivas en la ocupación prehistórica del yacimiento de Peñalosa (IIIA y IIIB) (2). Los niveles estratigráficos de la fase más antigua (IIIB) están muy mal conservados como consecuencia de la reestructuración espacial que se hace en la siguiente fase (IIIA). En este momento el poblado se expande hacia el norte, bajando hacia el río Rumblar. Las dataciones de C-14 para este momento nos señalan el final del poblado entre el 1400 y 1500 a.C. (Contreras et alii, 1991), no pudiendo precisarse por ahora el momento de fundación del poblado.

\section{LA ORGANIZACIÓN DEL ESPACIO EN PEÑALOSA}

\section{Urbanismo}

El esquema urbanístico de Peñalosa responde a los patrones típicos de la Edad del Bronce en el Sureste. Se adapta perfectamente a las características morfológicas del terreno aterrazando las laderas del cerro a través de la construcción de grandes muros de pizarra que recorren longitudinalmente dichas laderas y otros que, perpendicularmente a los anteriores y transversales a la pendiente, organizan escalonadamente el espacio destinado a las viviendas, que cuentan además con compartimentaciones. Así en cada una de las terrazas artificiales la distribución espacial viene marcada por la existencia de varias unidades de habitación de variado tamaño y complejidad. En todas ellas se documentan diversos espacios dedicados tanto a acti-

(2) Las fases I y II de Peñalosa corresponden a esporádicas ocupaciones de época medieval y romana respectivamente, hasta ahora sólo documentadas en la forma de grandes fosas y también de un enterramiento de incineración en urna. La ocupación altomedieval del entorno de Baños de la Encina fue bastante importante tal y como demuestra el propio castillo de Baños de la Encina en el que también hay restos del Calcolítico y posiblemente de la Edad del Bronce (Nocete et alii, 1986; Lizcano et alii, 1990) y las "granjas" localizadas en los bordes del pantano del río Rumblar, que debieron formar parte de un hábitat disperso desaparecido con los conflictos de fines del Califato. vidades domésticas como de producción especializada (Lám. II). Los distintos grupos de unidades habitacionales están perfectamente comunicados por una serie de calles y pasillos estrechos que van recorriendo el poblado y que ponen en comunicación las distintas áreas de habitación. En Peñalosa se han distinguido cuatro grandes áreas: Terraza Inferior, Terraza Media, Terraza Superior y Fortificación, en base a las zonas de excavación (Fig. 2).

El poblado está defendido naturalmente en la parte occidental, mientras que en la oriental está cerrado por un gran muro, reforzado con bastiones macizos, y que a su vez dirigen la estructuración del espacio en la fase IIIA. En él se ha localizado una puerta estrecha de acceso que conduce a un pasillo zizagueante y fácilmente defendible. En la parte superior del cerro se han documentado restos de una fortificación central compleja, afectada en gran parte por las excavaciones antiguas (Lám. III).

\section{Actividades de producción y consumo. La uni- dad doméstica}

Se han determinado en la zona excavada un total de 10 Unidades de Habitación -UH- (Contreras et alii, 1993a, 1993b) que incluyen diversos espacios separados (Complejos Estructurales, $\mathrm{CE}$ ), dedicados a diferentes actividades, aunque a veces más de una compartió la misma zona. La especialización de los espacios en los poblados de la Edad del Bronce ya había sido referida en algunos lugares del sur de la Península Ibérica (Lull, 1983; Molina et alii, 1986), habiéndose señalado también para algunos poblados "especializados en la coerción" de la Edad del Cobre (Ruiz et alii, 1986; Nocete et alii, 1987; Nocete, 1994) y existiendo también en momentos del Neolítico Final en estructuras muy diferentes excavadas en el suelo y que tradicionalmente habían sido desestimadas bajo el nombre genérico de silos (Lizcano et alii, e.p., 1993).

En este contexto lo importante en la configuración del espacio en el poblado de Peñalosa no es la especialización de las diversas áreas sino la consolidación de la unidad familiar reflejada no sólo en la presencia de las tumbas familiares (3),

(3) Como se ha destacado en otras zonas del sur de la Península Ibérica (Molina et alii, 1975; Carrasco, 1979; Chapman, 1991).

\section{T. P., 52, n. ${ }^{\circ} 1,1995$}




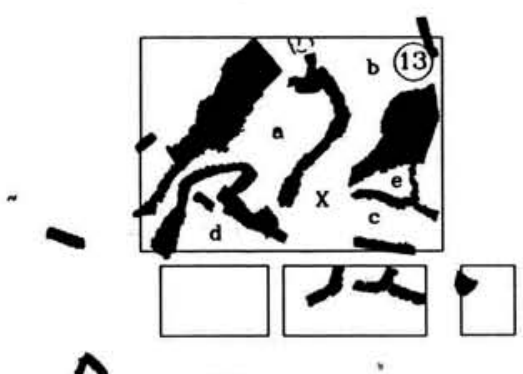

?
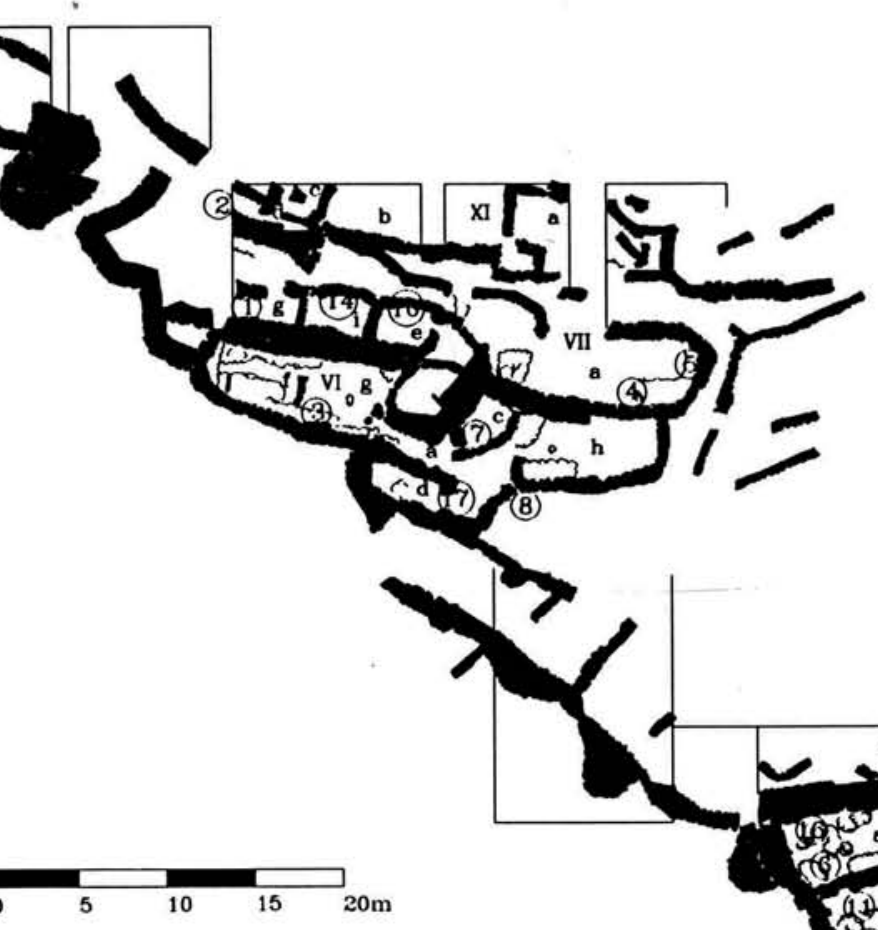

(12)

(II

(4)

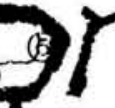

r

二

$\lim _{3}$

(8)
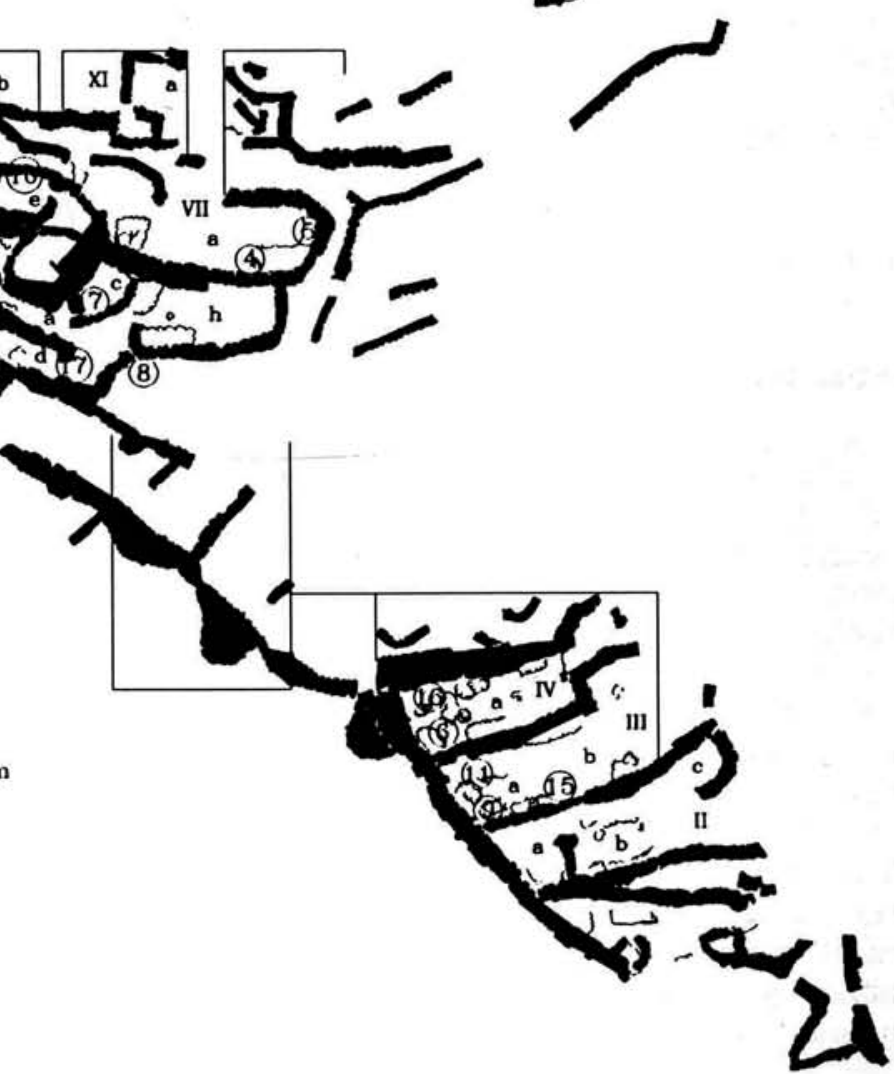

Fig. 2. Peñalosa: distribución de Unidades Habitacionales (I, II, III...), Complejos Estructurales (IIa, IIb, IIc...) y sepultu$\operatorname{ras}(1,2,3 \ldots)$.

sino también en la definitiva asociación a las unidades de habitación de determinadas actividades que antes se hallaban en algunos casos separadas, como la metalurgia del cobre a gran escala tal y como se había documentado en Los Millares (Arribas et alii, 1987; Delibes et alii, 1988; Moreno, 1993).
De tal manera en diferentes casas del poblado (UH I, II, V, VI) se han podido rastrear espacialmente diversas fases del proceso metalúrgico del cobre: molienda del mineral, reducción, fundición y vertido en moldes. No se aprecia una especialización de las viviendas en cada una de estas fases, tal como plantea Lull (1983: 319) 

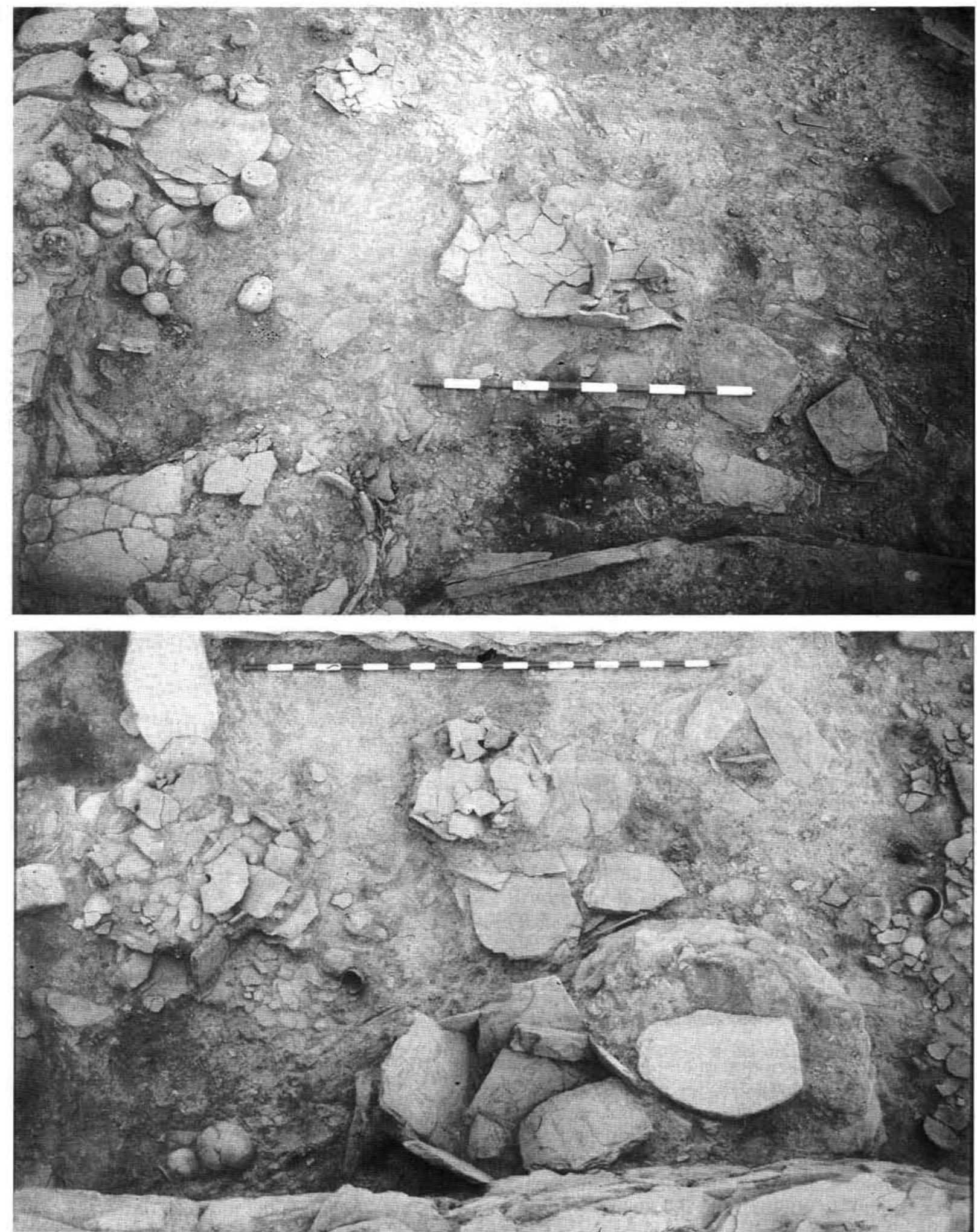

Lám. II. Peñalosa: Unidad Habitacional IV. Contextos de actividad textil (a) y de transformación y almacenaje de grano (b).

T. P., 52, n. ${ }^{\circ} 1,1995$ 


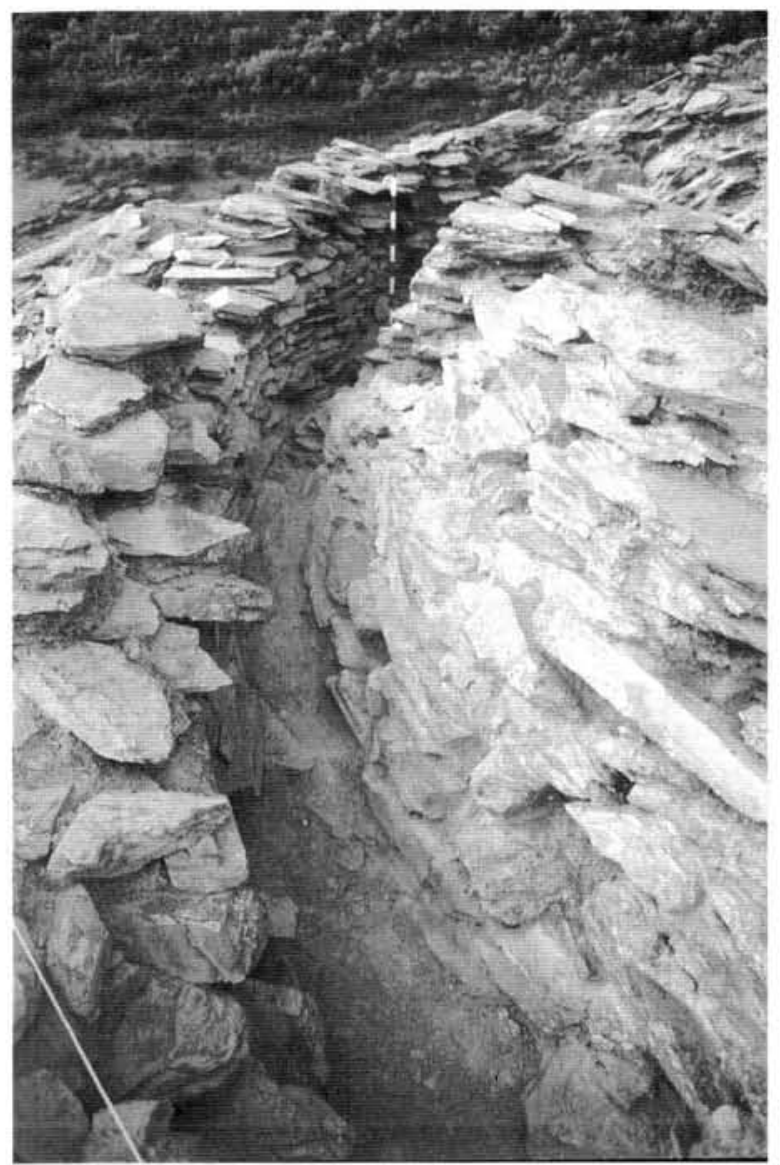

Lám. III. Peñalosa: fortificación.

p. ej. para La Bastida de Totana (Murcia), sino que se realizan en distintas habitaciones de la misma casa. Algunos de los espacios dedicados a la metalurgia solían estar descubiertos como se manifiesta en los CE VIh, VIg y IIa (Figs. 3 y 4 ).

Un hecho que las excavaciones aun no han podido demostrar es si la presencia de múltiples espacios dedicados a la metalurgia en algunas casas (VI) está en relación con la posición social de sus ocupantes, que viene indicada por la presencia de cerámicas específicas en el contexto doméstico (incluyendo algunas cerámicas decoradas) y por el ajuar y el tratamiento de los cadáveres que incluye. En La Bastida de Totana (Murcia), Lull (1983: 319 y 324) plantea esa diferenciación en base a la cantidad de instrumentos y la presencia de elementos de prestigio/riqueza en los enterramientos infantiles que incluía la habitación/casa XXI/XI. El problema fundamental es que al noroeste de Peñalosa el panta- no del Rumblar con su actividad erosiva ha cercenado el extremo de muchas de las casas documentadas en el área más baja (especialmente la conexión entre las UH III y IV).

Más fácil es, de momento, comparar el ajuar cerámico presente en las diversas casas. El análisis morfométrico de la muestra (Contreras et alii, 1992) indica una diferenciación entre los elementos presentes en la Terraza Media y los que localizamos en la Terraza Inferior, y sobre todo, y respecto a los demás, destacan los materiales que constituyen la casa VI. Incluso hay indicios para señalar la diferenciación entre las casas en que está presente la metalurgia y las que no, naturalmente dejando a un lado los elementos propiamente relacionados con esta actividad (crisoles, vasijas-horno, moldes, etc.), aunque debemos precisar que esa relación se deriva de la oposición entre almacenaje de grano a gran escala y metalurgia en cuanto a las subdivisiones de las casas, y a su vez entre la diferente representación de las especies animales consumidas en la Terraza Inferior y en la Superior.

\section{Almacenamiento de determinados productos. La diferenciación entre las unidades familiares}

La oposición entre los espacios dedicados al almacenaje de grano (Lám. IIb) y los dedicados a las actividades metalúrgicas se da al interior de las mismas casas, como exponen claramente las UH. II y VII. Sin embargo, la modalidad de los sistemas de almacenaje y la cantidad de recipientes empleados varía en cada caso. Merece destacarse el CE IVa (Lám. IV) por el gran número de orzas que contenía así como por la gran cantidad y variedad de especies cereales, acompañadas de malas hierbas (Contreras et alii, 1992).

Ello nos permite aproximarnos con más cautela a los restos de recipientes de almacenaje recuperados en la zona más elevada y más fuertemente fortificada del yacimiento (UH X), descartando un control centralizado del almacenaje de grano (Contreras et alii, 1987, 1991). Por ello, viendo en conjunto los datos del registro arqueológico de Peñalosa, nos inclinamos por valorar otros elementos como más claros exponentes de la diferenciación social y objetivos del poder. Nos referimos a los rebaños, especialmente los compuestos por bóvidos y équidos cuyos restos se concentran en la zona alta del poblado. Esto constituye una prueba indirecta 


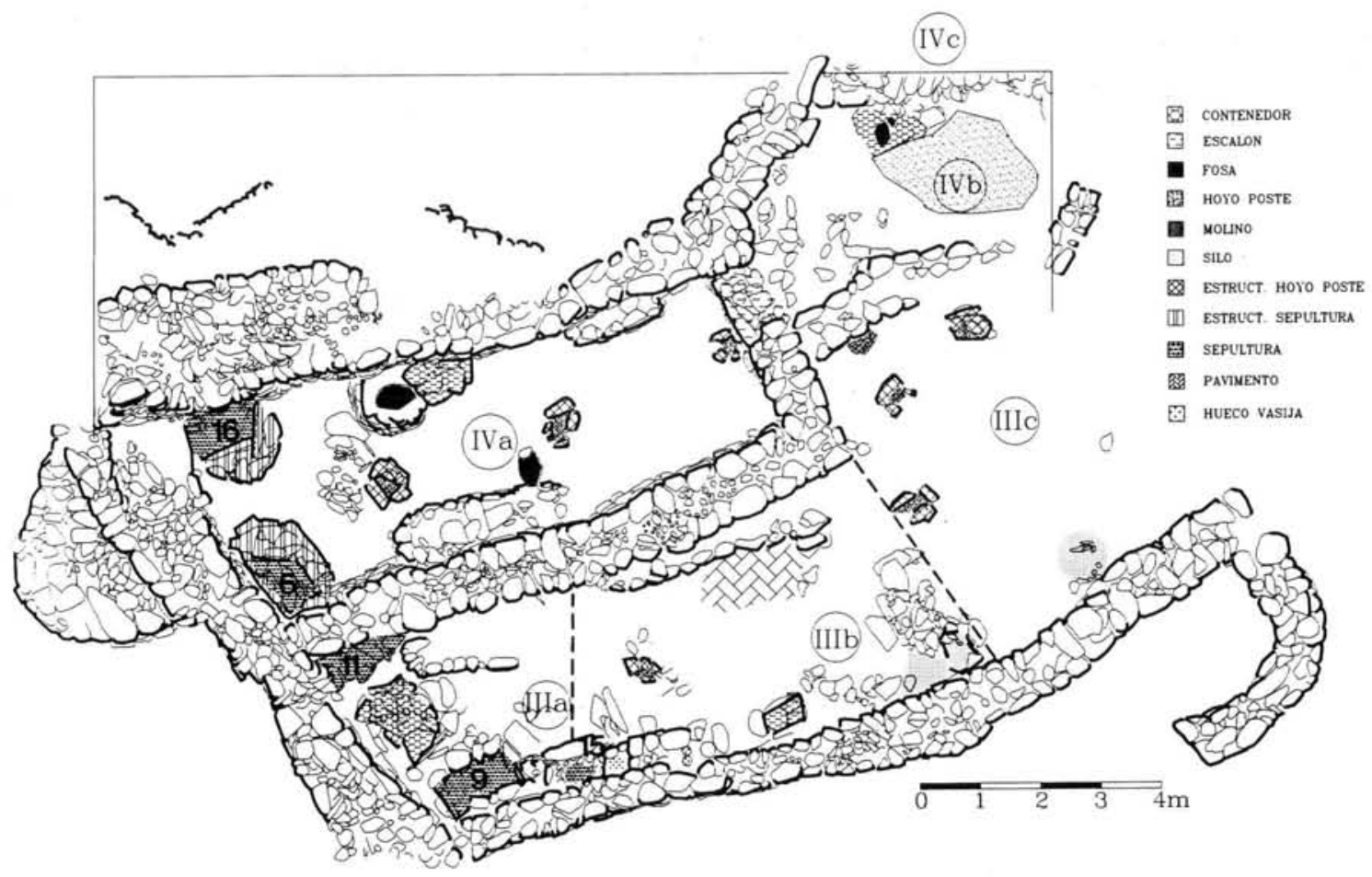

Fig. 3. Peñalosa: planta de las Unidades Habitacionales II y III y distribución de sepulturas.

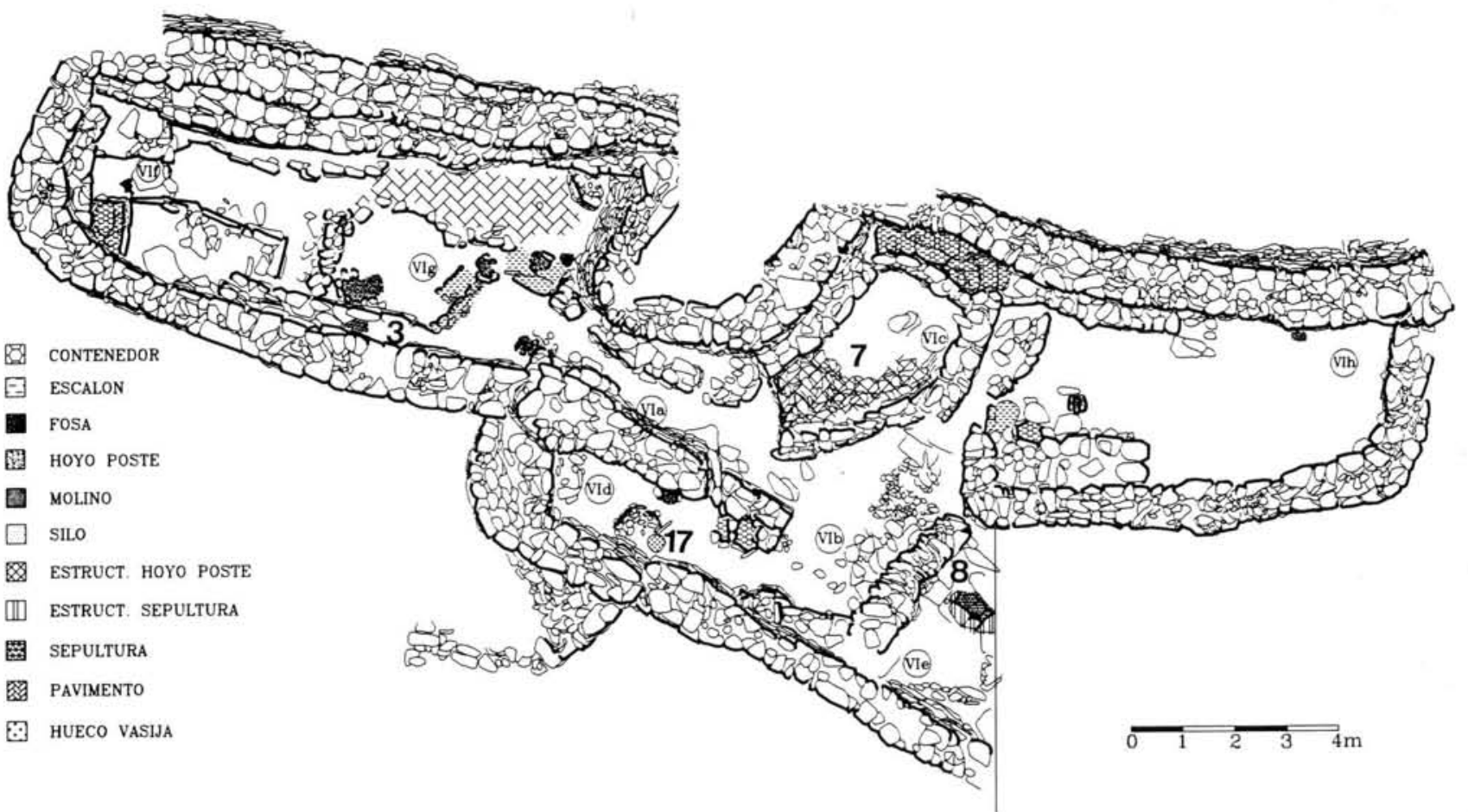

Fig. 4. Peñalosa: planta de la Unidad Habitacional VI y distribución de sepulturas.

T. P., 52, n. ${ }^{\circ} 1,1995$ 


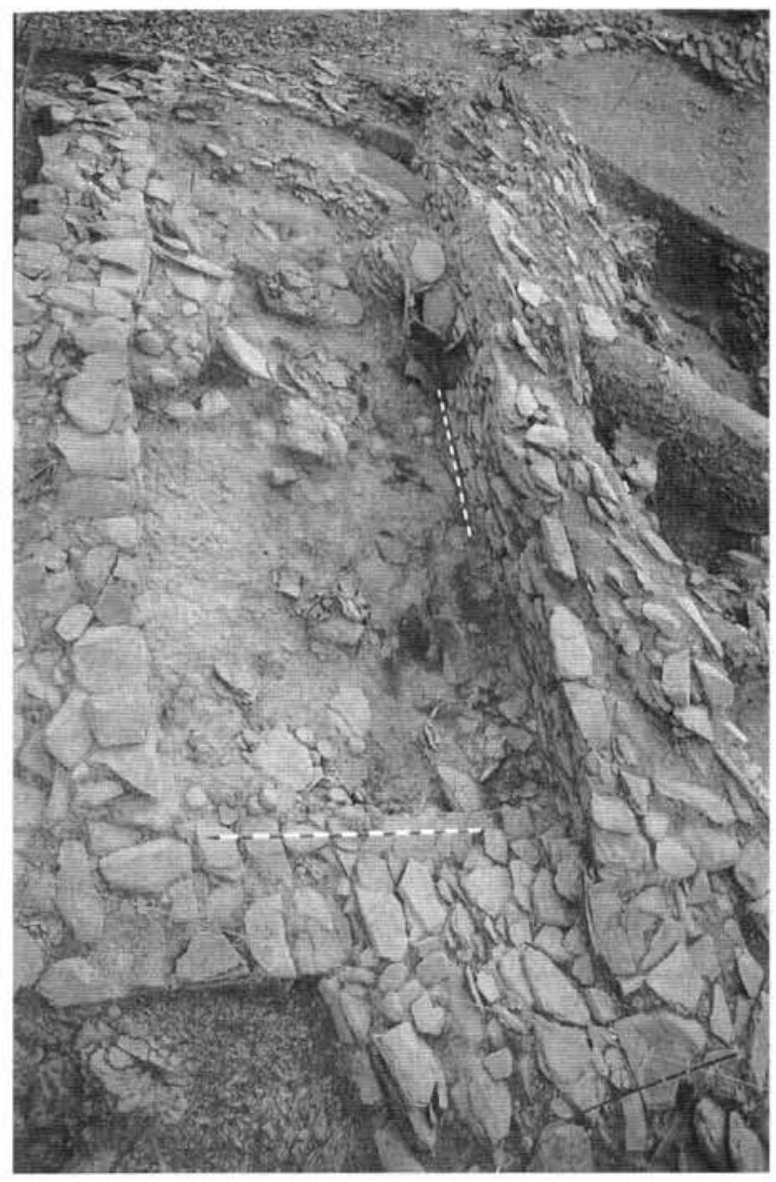

Lám. IV. Peñalosa: Unidad Habitacional IV.

de la apropiación de los rebaños de forma familiar o, al menos, de su consumo en tal forma.

La reproducción del poder de estas élites en esta zona serrana se basó sin embargo en el control de la canalización del metal que aportaba beneficios relativos al resto de la población y que garantizaba las contrapartidas desde los centros políticos de la Depresión Linares-Bailén; pero que también servía aquí para exhibir el rango de los poderosos, su derecho a la propiedad de determinados elementos de acumulación de riqueza (como los animales arriba referidos), y en definitiva la dirección de la comunidad. Así aun cuando suprimamos del total de équidos y bóvidos de las casas VI, VII y X el ajuar faunístico de la tumba $\mathrm{n}^{\circ} 7$, localizado, como después señalaremos, en una estructura aneja, la diferencia con las otras zonas del poblado sigue siendo importante y además la movilización en favor de los antepasados resulta aún más significativa, especialmente al incluir las partes anatómicas de más valor nutritivo.

\section{Símbolos domésticos y producción económica. La cerámica decorada y su distribución desigual}

Si los elementos decorados están presentes en casi todas las casas de Peñalosa (4) ni su cantidad ni su variedad de motivos es comparable, destacando de nuevo en estos aspectos las UH VI y VII. Prescindiendo de la descripción de los motivos decorativos presentes, debemos resaltar su asociación con espacios inmediatos a la producción metalúrgica, a excepción de la casa III, cuyo límite oeste no se ha podido determinar debido a la erosión del pantano. Ello abre interesantes posibilidades en cuanto al origen de estos elementos en conexión con los motivos campaniformes, que numerosos autores (Shennan, 1982) han vinculado con la expansión de la metalurgia. No debe olvidarse en este caso que en las estribaciones meridionales de Sierra Morena y las zonas aledañas la metalurgia se constata desde el Cobre Final (Pérez et alii, 1992a, 1992b, 1992c; Nocete, 1994). Otra posibilidad es más indirecta y vincula estos elementos con las poblaciones meseteñas a través del río Grande (5), aunque, en cualquier caso, la metalurgia presente en Las Motillas, al menos en las fases de segunda fundición y vertido en moldes, tie-

(4) Se trata de un elemento que podría diferenciar las formaciones sociales del "Horizonte argárico del Alto Guadalquivir" de aquéllas que se sitúan en el oriente granadino, donde los elementos decorados parecen más escasos o ligeramente más tardíos (Molina, 1978), y en el caso de Purullena también mucho más puros y relacionables con la Meseta (Molina y Pareja, 1975; Molina, 1978; Contreras, 1986). En otras zonas del valle del Guadalquivir, exteriores a tal horizonte, también se ha constatado el fenómeno (Aubet et alii, 1983), que permite la conexión con el complejo "Horizonte Campaniforme" de dicho valle (Caro, 1989). Sin embargo, o bien se ha negado la evidencia queriéndola retrasar en el tiempo (Martín de la Cruz, 1989), o bien se ha recurrido a la misma explicación difusionista con respecto al boquique y a la excisión que ahora algunos autores (Caro, 1989) señalan que se difundirían desde el Guadalquivir a la Meseta, olvidando que tampoco allí hay rupturas con el Campaniforme (Delibes y Fernández-Miranda, 1986-87; incluso al nivel de los enterramientos Jimeno, 1984; Esparza, 1990) a través de lo que se ha denominado Proto-Cogotas.

(5) O más al oeste, a través del río Jándula, una vía tradicionalmente casi tan importante como Despeñaperros.

T. P., 52, n. ${ }^{\circ} 1,1995$ 
ne un papel poco relevante en sus actividades económicas (Molina et alii, 1979; Nájera y Molina, 1977; Nájera, 1984) (6).

Sería útil relacionar estos elementos decorados con la posición social de los habitantes de las casas en las que aparecieron no sólo en Peñalosa sino en otras zonas del "Horizonte Argárico del Alto Guadalquivir" alejadas de los filones (7). En este sentido contamos con algunos datos que pueden apoyar la hipótesis de la relación de estos elementos con determinadas capas de la población. Así, en las excavaciones de la provincia de Jaén frente a la concentración documentada en Iznatoraf (Ruiz et alii, 1986) contamos con algunos fragmentos decorados en los niveles de habitación de Baeza (Zafra y Pérez, 1992) y muy pocas referencias en Úbeda (Ruiz et alii, 1986), lo que sugiere que estos elementos se concentraban en todos los casos en determinadas zonas del poblado, y que la presencia diferencial de la cerámica decorada no es así el resultado de un mayor o menor arcaísmo como se había sugerido (Ruiz et alii, 1986), sino la combinación de la concentración en determinadas viviendas y la aleatoriedad de los sondeos arqueológicos.

(6) Lo cual no implica que deba rechazarse o minusvalorarse la actividad metalúrgica en todas las zonas de la Submeseta Sur como pretende Ruiz Taboada (1993:314) dado que la propia evidencia presentada por el autor desmiente este hecho (sobre todo en el yacimiento de El Guijo). Indudablemente no existe comercio en sentido estricto pero ello no supone que no existan redes de distribución entre las élites de las diversas formaciones sociales y sobre todo relaciones tributarias entre los diversos poblados de una misma formación social (como incluso parece plantear para los pequeños poblados agrícolas del valle del Algodor). En otro orden de cosas su valoración de la actividad ganadera y los desplazamientos no desemboca en una apreciación del papel del ganado en sí como elemento de acumulación y jerarquización social sino sólo como un alimento o un bien intercambiable por elementos presuntamente permanentes como el metal (Ruiz Taboada, 1993: 318).

(7) El "Horizonte Argárico del Alto Guadalquivir" será objeto de la segunda parte de este trabajo (Trabajos de Prehistoria, 52, 2, 1995), pero adelantamos aquí que utilizamos el término para referirnos a aquellas comunidades del este y norte de la provincia de Jaén que tanto por su patrón de asentamiento como por las características internas del habitat, incluyendo la generalización de los enterramientos bajo las viviendas, se relacionan con las comunidades argáricas del Sureste. Pero remarcamos el hecho de que ambos grupos no forman parte de una única Formación Social y que ni siquiera dentro de cada uno de ellos podemos hablar de unidad social en tales términos.

\section{EL REGISTRO FUNERARIO EN PEÑALOSA}

\section{Las sepulturas: tipos y distribución}

\section{La presencia diferencial de las sepulturas en los distintos espacios domésticos y en las distintas fases}

Las sepulturas se caracterizan no sólo por sus rasgos formales (cista o urnas), sino también por su localización, bajo las unidades de habitación. El poblado, por tanto, funcionaba como lugar de morada de los vivos y de los muertos. Esto traduce de una manera clara la significación que para los habitantes de Peñalosa tenían sus difuntos, a los cuales no solo rendían cultos rituales, cifrados en las creencias relativas al "más allá", sino que también llegaban a venerarlos como antepasados notables, manteniéndolos cerca, seguramente para simbolizar de una manera directa la ascendencia que algunos vivos mostraban con orgullo, sobre todo en aquellos casos en que importaba justificar conceptos de sangre y linaje.

El ritual es siempre la inhumación, individual o doble, casi siempre incluyendo en esos casos hombre y mujer, y en algunas ocasiones niños. Esto nos demuestra el gran papel que dentro del seno de las organizaciones sociales de la Edad del Bronce del sur peninsular habían llegado a desempeñar los núcleos familiares y los individuos, siendo elementos capaces de sugerir la ostentación del prestigio, la alcurnia, la riqueza y el poder.

Las sepulturas son un buen indicador para poder delimitar los distintos conjuntos espaciales, ya que normalmente cada unidad habitacional cuenta con una o dos sepulturas. No en todos los espacios de Peñalosa se han localizado enterramientos ni tampoco existe una representación igual para las fases IIIA y IIIB. Los escasos restos humanos de la fase IIIB se han recuperado bajo el CE VIIe, afectados por la construcción de uno de los muros que lo delimitan y mostrando cómo en esa primera fase los enterramientos se realizaron en el espacio abierto que quedaba junto al muro de cierre original del poblado (Contreras et alii, 1991).

Otras evidencias sobre enterramientos en espacios abiertos no pueden situarse en una fase $\mathrm{u}$ otra y se reducen a hallazgos superficiales de determinados recipientes y a la tumba 12 en el farallón rocoso, muy afectada por la erosión e 
imposible de asignar a cualquiera de los dos momentos.

Sin embargo contamos con una documentación mucho mejor de los enterramientos que se sitúan al interior de las viviendas en la fase IIIa, especialmente porque, debido al abandono del poblado, no han sido afectados por construcciones posteriores. Hay por el contrario determinados espacios en los que no se producen inhumaciones, especialmente en las Terrazas Media y Superior de la ladera norte, relacionados en muchos casos con las actividades metalúrgicas.

En la Terraza Superior la mayoría de las tumbas de la fase IIIA se realizaron en habitaciones de uso exclusivamente funerario, en algunos casos embutiendo verdaderas cistas en espacios estrechos (CE XId y VIIg). Por el contrario, hemos de señalar que en el complejo estructural VIIa, donde no podemos relacionar los enterramientos con las actividades que allí tuvieron lugar, debido a las alteraciones producidas por una fosa romana en el extremo oriental y a la erosión en el occidental, tenemos inhumaciones en huecos de la roca revestidos y también un pithos con enterramiento infantil (Lám. Va).

En la Terraza Media la tumba 7 (Lám. Vb), construida en el centro de la vivienda (CE VIc) a través de una estructura de mampostería de grandes dimensiones, adquiere un carácter verdaderamente monumental (Contreras et alii, 1991). En la Terraza Inferior las tumbas localizadas se sitúan junto al muro de fortificación, al fondo de las casas, en cistas embutidas en estructuras de mampostería utilizadas como bancos después de la inhumación, sobre los que se sitúan recipientes de almacenaje u otros elementos, lo que marca aún más la continuidad entre la vida y la muerte. Por último, dados los datos obtenidos de las excavaciones en extensión en las zonas arriba referidas, podemos plantear como hipótesis la existencia de espacios destinados a los enterramientos en el área inmediata a la fortificación central.

Estas diferencias en situación y tipología de las tumbas tienen una importante relación con la desigualdad social a la que después nos referiremos tras estudiar los ajuares y las características físicas de los esqueletos.

Conviene recordar aquí que las sepulturas bajo las viviendas quedan enmascaradas para el resto de la sociedad en lo referente a contemplación, percepción de su monumentalidad y contenido; aunque, por un lado, la continuidad con los vivos justifica la herencia de éstos, su posición y, por otro lado, la fuerza simbólica de la tumba queda aumentada por su continente, las viviendas entre las que ya se apreciaba la desigualdad, incluso como veremos entre los que viven y mueren en ellas, y que en cierto modo podrían considerarse una nueva forma de túmulo con respecto a las tumbas que incluye.

\section{El número de inhumados y el carácter del poblado}

Aun teniendo en cuenta las pocas fases de ocupación documentadas en el poblado de Peñalosa durante la Edad del Bronce (fases IIIA y IIIB), las tumbas hasta ahora localizadas pueden considerarse muy escasas en relación a la superficie excavada en profundidad. Así con la salvedad de que la introducción de varios cadáveres, emparentados sin duda en la misma tumba, y el hecho de la concentración de estas estructuras funerarias en determinados espacios pueden distorsionar los resultados, podemos señalar que no toda la población accedía al enterramiento en el interior del poblado. En cualquier caso, debemos resaltar la interesante diferencia que parece apreciarse en la proporción de enterramientos por superficie excavada entre Peñalosa y los poblados que consideramos políticamente centrales en la zona, tanto por sus antecedentes o perduración como por los resultados de algunas excavaciones en la zona de La Loma de Ubeda (Zafra, 1991; Zafra y Pérez, 1992). En estos últimos, la concentración de enterramientos, aun teniendo en cuenta la superposición de fases estratigráficas, es mucho más evidente (Ruiz et alii, 1986; Hornos et alii, 1987; Zafra, 1991; Zafra y Pérez, 1992).

Parecería así un poco sorprendente esta diferencia si se contrasta con la argumentación de que en la "periferia" de estas formaciones sociales, en los poblados metalúrgicos de los límites de su expansión hacia el oeste, la abundancia de material metálico conduce a un mayor enmascaramiento de la desigualdad por la emulación entre las diferentes unidades familiares. Este viene auspiciado también por la necesidad de mantener la cohesión interna en las cercanías de la frontera de las formaciones sociales que ocuparon la Depresión Linares-Bailén, entendida ésta, indudablemente, en términos políticos, y que viene sugerida por las características del hábitat, cultura material mueble y enterramientos de la zona de Andújar (Pérez et alii, 1992a). 
a

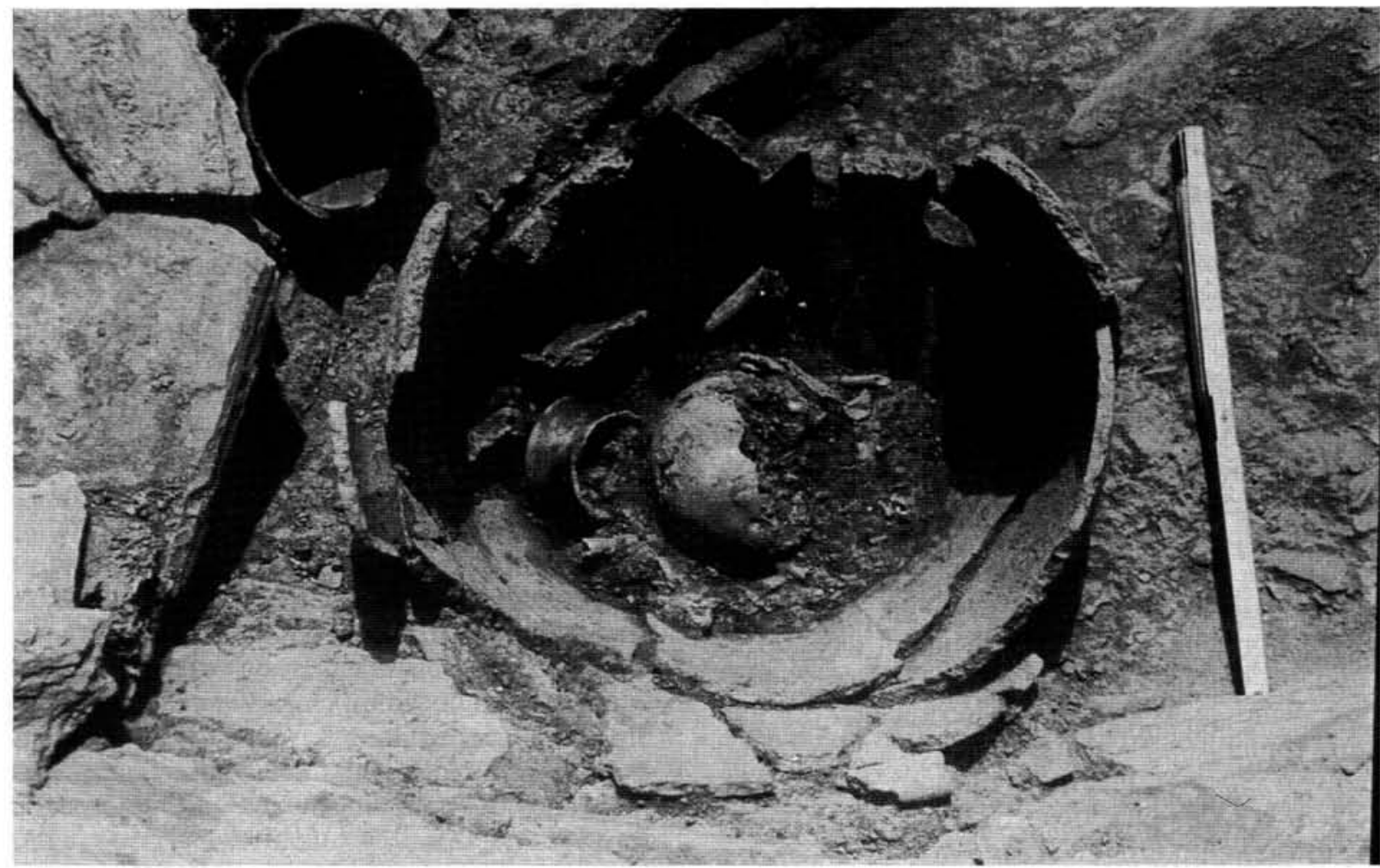

b

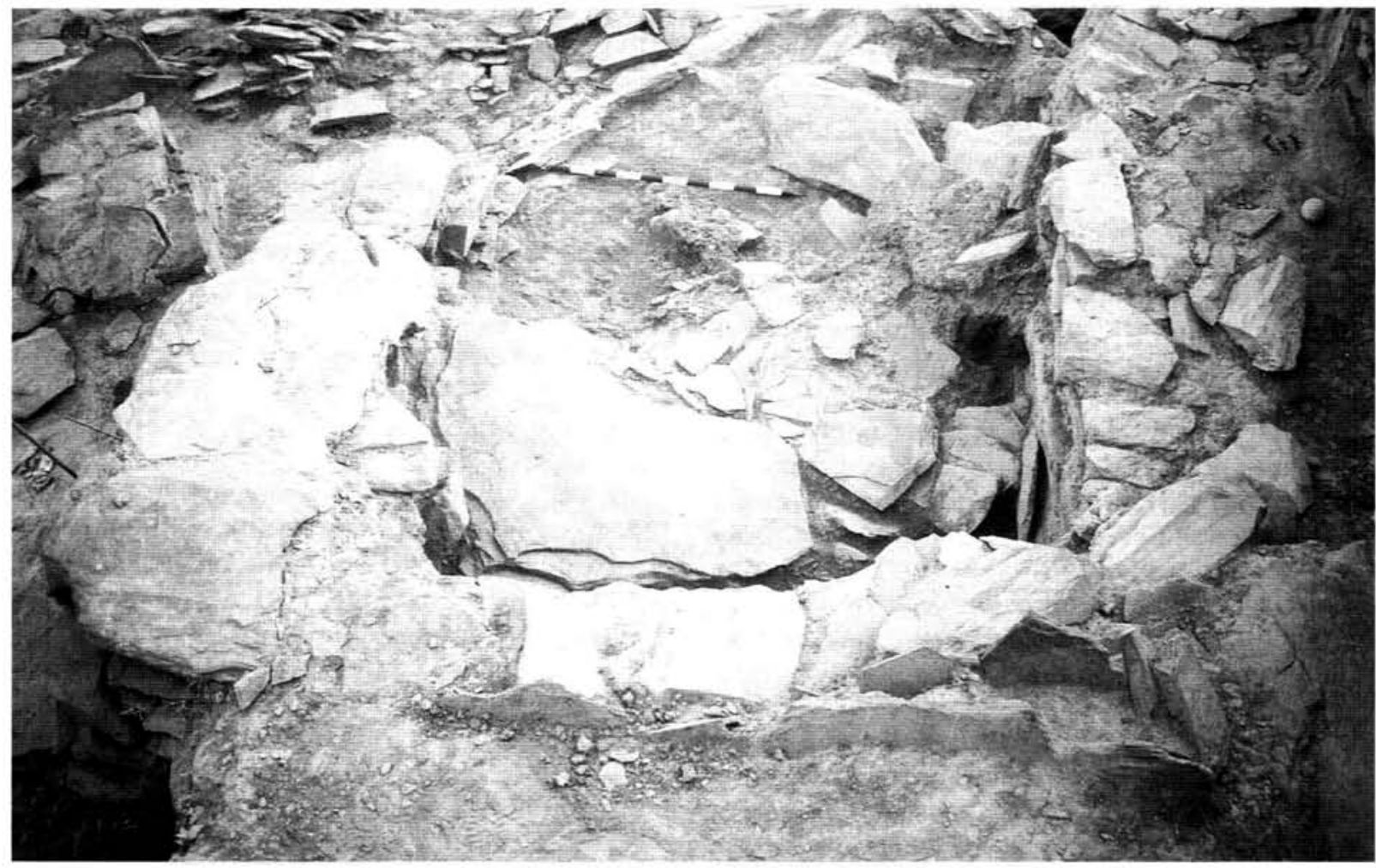

Lám. V. Peñalosa: sepulturas 4 (a) y 7 (b).

T. P., 52, n. ${ }^{\circ} 1,1995$ 
Sin embargo, creemos que lo importante en este caso era establecer el sistema en un primer momento, simbolizar la posición social en la construcción de la casa, en los primeros enterramientos y en su contenido. Ello además impediría el empobrecimiento exagerado de la capa social de base, al no tener que movilizar constantemente recursos en la emulación de los nobles, evitando de esta forma, temporalmente, la ruptura del sistema social vigente.

\section{El estudio antropológico}

\section{Metodología}

Los enterramientos han sido analizados individualmente identificando todas las piezas, en los casos en que ello fue posible, para obtener información sobre sexo, edad, patología, caracteres cualitativos, dimorfismo sexual, actividades ocupacionales, etc. Para ello han sido utilizadas las técnicas antropológicas habituales (Olivier, 1960; Bass, 1971; Finnegan, 1978; Ferembach et alii, 1979; Lovejoy et alii, 1985; Ortner y Putschar, 1985).

El material se encuentra en mal estado de conservación, debido posiblemente a la composición química y acidez del suelo. En general son los huesos largos y piezas dentarias los mejor preservados. La metodología empleada, gracias al proceso de flotación de tierra tanto del suelo de ocupación como del sedimento procedente de recipientes, ha hecho posible encontrar piezas dentarias de individuos infantiles.

\section{La diferente representación de sexos y edades}

En el total de las 17 tumbas excavadas en Peñalosa la representación de los sexos, pese al problema de identificación de los individuos infantiles (hasta 12 años), muestra importantes diferencias, hasta el punto de que los hombres, en los casos determinados, doblan a las mujeres. Ello es consecuencia directa del hecho de que en la mayoría de las ocasiones las mujeres acompañan en las tumbas a los hombres (excepto en la tumba 9).

En este sentido es significativo que en las tumbas con dos inhumaciones encontremos bien enterramientos de individuos infantiles con adultos (tumbas 4 y 13), bien un hombre y una mujer (tumba 1), mientras en los enterramientos triples encontramos, en los dos casos hasta aho- ra excavados, dos varones y una mujer (tumbas 2 y 7 ).

También en cuanto a las edades (Tabla 1) la distribución es muy diferente, y si la ausencia de individuos seniles puede indicar la esperada baja esperanza de vida, el corto número de niños no se relaciona con la mortalidad infantil que se daría en la época, hasta el punto de que sólo contamos con un individuo entre los 6 y los 12 años.

Un hecho interesante, en relación a los enterramientos infantiles es su importante concentración en la UH III (tumbas 11, 15A y 15B), especialmente por la tipología de la tumba 15 (Lám. VI), al tratarse de recipientes embutidos en un banco y con restos de niños al interior, en el caso de la $15 \mathrm{~A}$ con indicios de combustión.

\section{Las distintas enfermedades y el esfuerzo diferen- cial. La apropiación del trabajo}

El individuo depende del medio que le rodea como fuente de vida, viéndose sometido a distintos factores de estrés que afectan a su adaptación. La respuesta a la presión ambiental depende entre otros factores de la edad, el sexo, la resistencia y la susceptibilidad genética de cada individuo (Goodman et alii, 1988; Woods et alii, 1992), al igual que de la duración y, sobre todo, la severidad del estrés al que se vea subordinado (Walker y Hollimon, 1989).

Entre los numerosos marcadores de estrés que permiten evaluar las respuestas adaptativas del individuo al medio ambiente, hemos elegido un total de diez indicadores: cribra, hiperostosis, hipoplasia, caries, pérdida ante mortem, parodontosis, fracturas, periostitis, exóstosis y artrosis. Las lesiones más frecuentes son la artrosis, exóstosis, periostitis (respuesta inflamatoria del periostio que tiene origen en lesiones traumáticas, enfermedades infecciosas, deficiencias nutricionales y trastornos hemodinámicos), así como las relacionadas con las piezas dentarias, caries e hipoplasia (deficiencias en el grosor del esmalte dentario relacionado con fases de detención del crecimiento como consecuencia de diversos factores, entre otros períodos de malnutrición).

El estudio paleopatológico indica que al menos el $50 \%$ de los individuos analizados presentan algún tipo de lesión. Las artrosis podrían estar relacionadas con fenómenos de actividad física prolongada en el tiempo y esta hipótesis, 
Tabla 1. DISTRIBUCIÓN DE LA MUESTRA POR SEXO Y EDAD

\begin{tabular}{|c|c|c|c|c|c|c|c|c|c|c|c|c|c|c|}
\hline & \multicolumn{2}{|c|}{ INFANTIL I } & \multicolumn{2}{|c|}{ INFANTIL. II } & \multicolumn{2}{|c|}{ JUVENIL } & \multicolumn{2}{|c|}{ ADULTO } & \multicolumn{2}{|c|}{ MADURO } & \multicolumn{2}{|c|}{ SENIL } & \multicolumn{2}{|c|}{ TOTAL } \\
\hline & $n$ & $\%$ & $\mathrm{n}$ & $\%$ & $\mathrm{n}$ & $\%$ & $\mathrm{n}$ & $\%$ & $\mathrm{n}$ & $\%$ & $\mathrm{n}$ & $\%$ & $\mathrm{n}$ & $\%$ \\
\hline Masculino & - & - & - & - & 1 & 9.1 & 8 & 72.7 & 2 & 18.2 & - & - & 11 & 47. \\
\hline Femenino & - & - & - & - & - & - & 3 & 60.0 & 2 & 40.0 & - & - & 5 & 21. \\
\hline Indeterminado & 5 & 71.4 & 1 & 14.3 & - & - & 1 & 14.3 & - & - & - & - & 7 & $\begin{array}{l}30 . \\
4\end{array}$ \\
\hline TOTAL & 5 & 21.7 & 1 & 4.3 & 1 & 4.3 & 12 & 52.2 & 4 & 17.4 & - & - & 23 & $\begin{array}{l}10 \\
0\end{array}$ \\
\hline
\end{tabular}

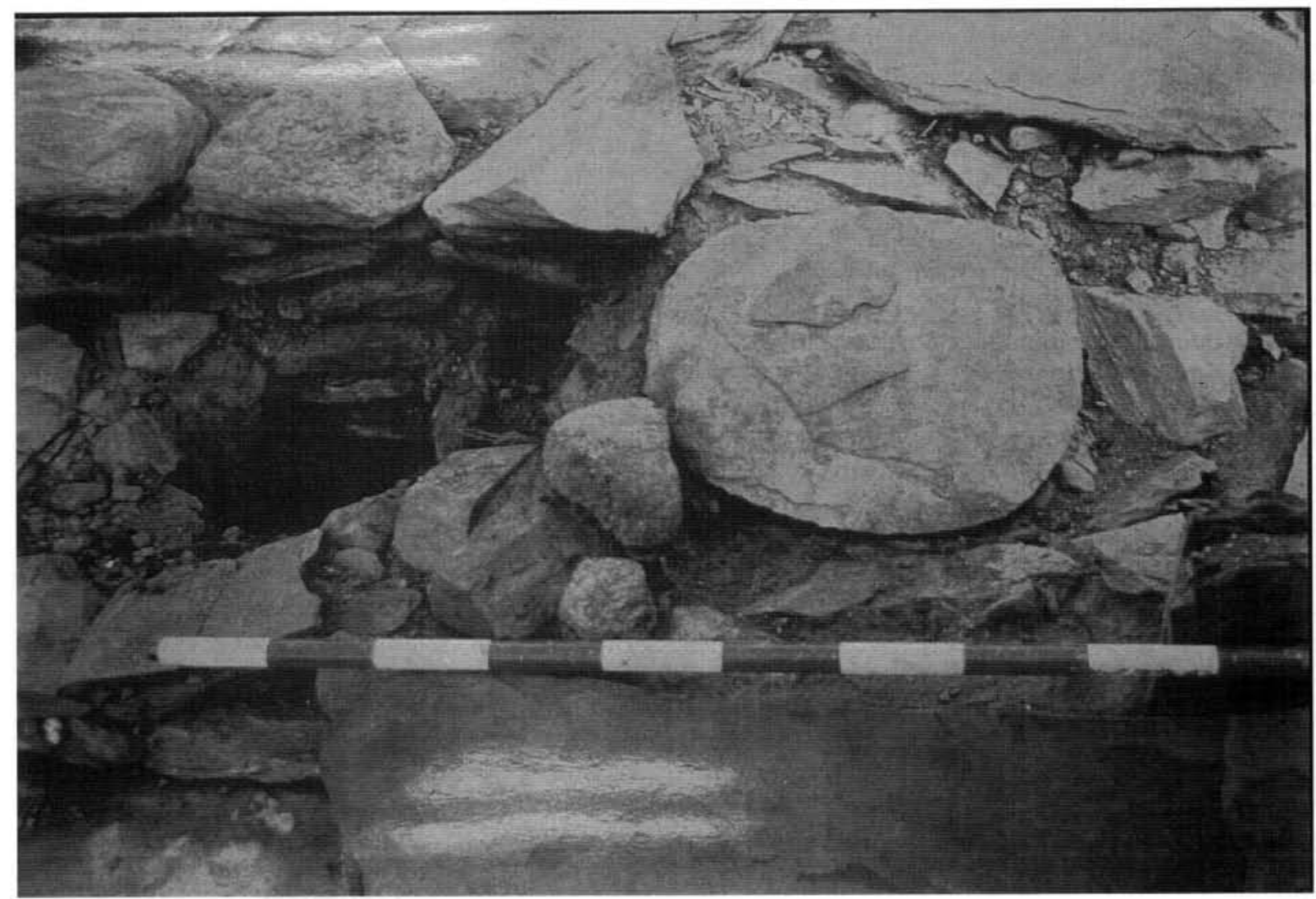

Lám. VI. Peñalosa: sepulturas infantiles 15 a y $15 b$.

estaría apoyada en la edad madura de la mayoría de los individuos afectados y en la actividad minera que sabemos se desarrolla en el poblado.

No se ha detectado ninguna patología inesperada. Es relativamente frecuente la existencia de hipoplasia dental y cribra orbitalia, conocidas ambas lesiones en series andaluzas del Bronce (Trancho et alii, e.p.), lo que indicaría que la población se vio sometida a situaciones de estrés durante la infancia. Mucho más común resulta la presencia de caries y parodontosis (reabsorción alveolar superior a los $3 \mathrm{~mm}$ que podría expli-

T. P., 52, n. ${ }^{\circ} 1,1995$ 


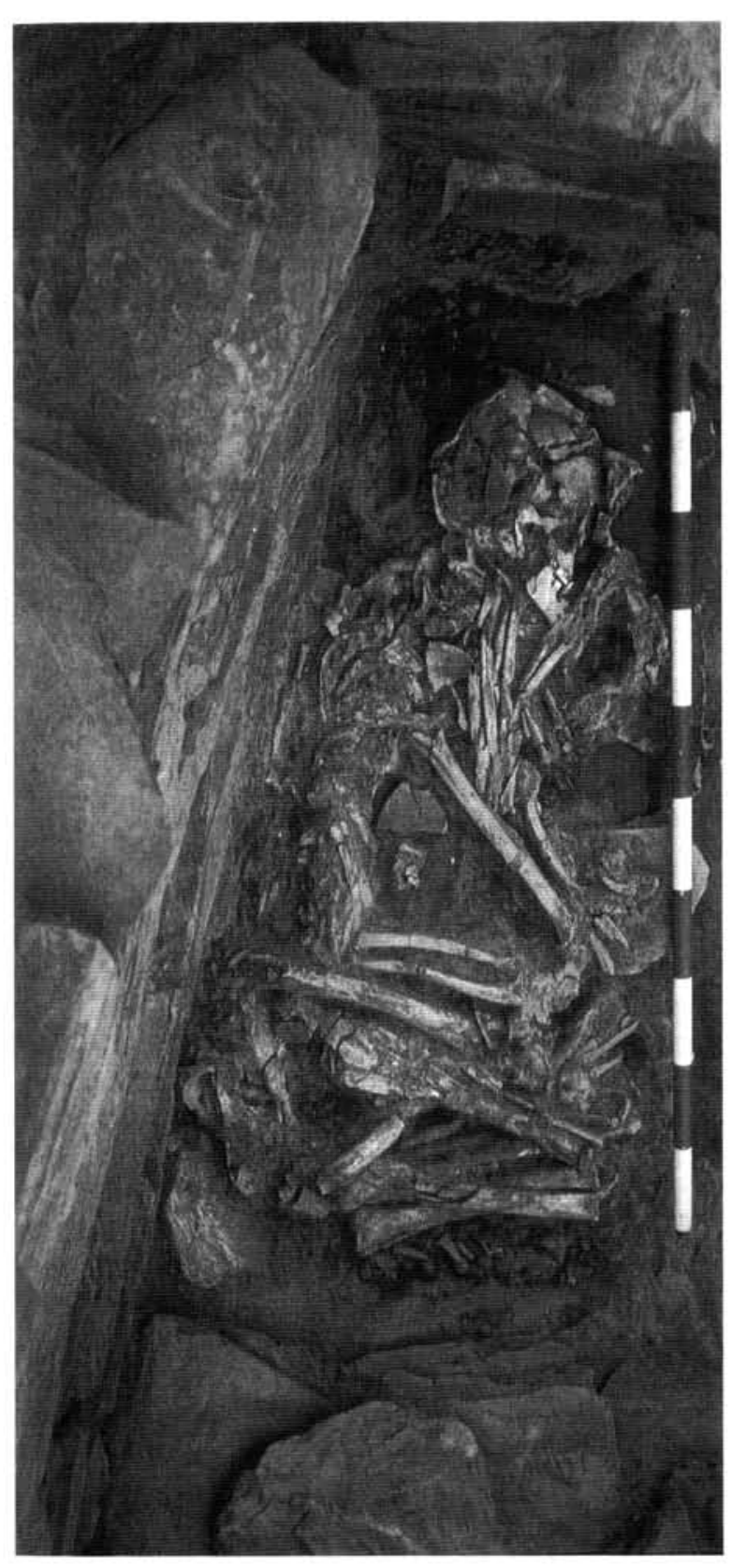

Lám. VII. Peñalosa: sepultura 2.

carse por una escasa higiene bucal y/o la menor resistencia tisular a los agentes bacterianos debido a una dieta deficiente) en los individuos adultos, mientras que las alteraciones más graves del tejido óseo, como la artrosis y exóstosis, suelen afectar a personas de edad avanzada. Llama la atención las patologías asociadas a la frac- tura de clavícula del varón de la Tumba 2 (Lám. VII) y la fractura del radio del varón de esa misma tumba, producidas muy probablemente por una caída.

Los datos paleopatológicos de Peñalosa muestran una importante diferenciación entre los individuos que se sitúan en la tumba 7 y los restantes. En casi todos los casos existen anomalías que pueden atribuirse a problemas nutricionales o de presión ambiental general, como la cribra orbitalia y la hiperostosis, y sobre todo la hipoplasia del esmalte relacionada con períodos de detención del crecimiento, localizada en cinco de los nueve individuos que conservaban los caninos permanentes, siendo destacable el hecho de que el individuo masculino adulto de la tumba 7 pese a conservar la mayoría de los caninos no presentaba tal lesión, aunque sí la tenía el juvenil de la misma tumba.

Más diferencias muestran las alteraciones relacionadas con los patrones de actividad, siendo especialmente importantes las malformaciones de los individuos masculinos de la tumba 2 (e incluso del individuo femenino de la misma tumba con exostosis) que cuentan con fracturas, periostitis, exostosis y artrosis. Lesiones importantes también se encuentran en los individuos masculinos adultos de las tumbas 10 y 12 , y en la mujer madura de la tumba 9 con artrosis. Pese a que esta enfermedad está también presente en las vértebras del varón adulto de la tumba 7 el hecho de que esta parte del cuerpo no se conserve en los otros individuos puede distorsionar las conclusiones, debiendo tenerse en cuenta además que pese a la abundancia de costillas y extremidades de esta tumba no se ha localizado en ninguno de estos elementos la referida patología.

Por otra parte la presencia de esthesopatías, lesiones claramente relacionadas con el sobreesfuerzo muscular, se da de nuevo en dos individuos de la tumba 2 (Lám. VII), donde también contamos con fracturas.

Aun teniendo en cuenta lo precario de la muestra creemos que los resultados prueban algunas de las hipótesis sobre jerarquización social que habíamos propuesto y cuyos resultados desarrollamos a partir de aquí.

\section{El ajuar y su significación}

Los elementos cerámicos localizados hasta ahora en las tumbas excavadas de Peñalosa muestran escasas similitudes con los que se han 
recuperado de las habitaciones (8). Muy problemática es, sin embargo, la localización de una copa en el CE IIa (UH II) que el estudio microespacial y estratigráfico ha permitido relacionar con un banco/cista construido en un momento avanzado del uso de la casa, como muestra la sustitución de un hoyo de poste por otro situado al otro lado del tabique que lo separa del CE IIb, y que se encuentra parcialmente violada como otras de la zona baja del poblado al descender las aguas y quedar al descubierto ante los expoliadores, por lo que no se ha incluido en el listado de sepulturas al no localizarse restos humanos en ella. El otro ejemplar de copa, decorado con mameloncillos junto al borde, se halló en la tumba 6, acompañando a una botella, dos pequeños cuencos y un puñal.

La mayoría de los materiales depositados en colecciones particulares proceden, como se esperaba, de sepulturas, según los resultados del análisis morfométrico multivariante que incluye como elementos típicos funerarios, junto a las copas, determinados vasos carenados, botellas y vasitos de fondo convexo.

En cuanto a las piezas metálicas de cobre, tampoco los grandes puñales se han recuperado fuera de las sepulturas, siendo punzones y puntas de flecha los hallazgos metálicos más corrientes en los contextos domésticos. En relación a esto hemos de señalar que los elementos metáli$\cos$ individuales de prestigio (puñales, hachas, etc.) debieron acompañar a los habitantes de Peñalosa cuando abandonaron el poblado y no así los recipientes pesados o los elementos fácilmente sustituibles.

Incluso en el caso de los brazaletes, aquéllos que proceden con seguridad del interior de sepulturas están realizados en plata, mientras otro localizado en superficie fue realizado en cobre, aunque también podía proceder de una sepultura destruida.

En general, la frecuencia de tumbas dobles y triples en el asentamiento de Peñalosa, teniendo en cuenta las que hemos excavado hasta ahora, impide precisar la asociación de elementos cerámicos y metálicos a un sexo determinado y, en cualquier caso, algunos de los elementos de

(8) Un fenómeno que se ha sugerido también para la provincia de Granada (Carrasco, 1979; Contreras, 1986; Contreras et alii, 1987-88) pero que no parece darse en la zona almeriense según los resultados de Fuente Alamo p. ej. (Lull. 1983: 237).

T. P., 52, n. ${ }^{\circ} 1,1995$ ajuar revelan lo problemático de tal adscripción y de la identificación sin estudios antropológicos previos, fenómeno que también se detectó en Purullena (Molina, 1983). En este sentido, las pulseras de plata presentes en la tumba 7 se relacionan con un enterramiento en el que los dos individuos mejor conservados son varones, aunque hay una mujer. Más importante aún es la asociación en la tumba 9 de un puñal a una mujer adulta, lo que habría que relacionar con la concentración en esta habitación (UH III) de enterramientos de niños menores de dos años en todos los casos, tanto en las tumbas $15 \mathrm{a}$ y $15 \mathrm{~b}$ (embutidas en el banco (Lám. VI) y utilizando recipientes medianos para la inclusión de los restos), como en la tumba 11 (adosada al muro sur y cubierta por una laja).

La asociación de ambos hechos, el enterramiento femenino con puñal y la concentración de niños, puede destacar la importancia del lazo familiar. Para explicar el ajuar incluido en la tumba 9 (puñal y punzón de cobre y tres vasos cerámicos) debemos tener presente la posibilidad de que el miembro masculino de la familia desapareciera en cualquier expedición, aunque por ello mismo no se puede descartar que a través de la madre el nivel guerrero asignado a esta familia se mantuviera para sus hijos supervivientes (los que lograran alcanzar la edad requerida), impidiendo así la caída de la familia en la servidumbre. De tal forma la oposición hombre/mujer habría pasado a segundo plano frente a la diferenciación en clases, lo que vendría avalado también por la asociación a enterramientos femeninos de ricos ajuares con adornos en metales preciosos y armas en las tumbas de Purullena (Molina, 1983).

Dos situaciones más hay que discutir en relación a este tema. En primer lugar el nivel de riqueza similar al de la tumba 9 que presenta el ajuar de la tumba 6 , aunque incluyendo la copa, un elemento que tradicionalmente se ha considerado que indica una elevada posición social (Molina, 1983; Lull y Estévez, 1986). En este sentido lamentablemente la otra sepultura que se localizaba en la UH IV (tumba 16) fue expoliada aunque los restos de un cuenco parabólico parecen indicar un ajuar similar. Del mismo modo en la UH II el hallazgo de una copa en las inmediaciones de una cista/banco expoliada nos reafirma en la consideración de las tumbas de esta parte del poblado, al menos las excavadas, como las correspondientes a la población gue- 
rrera/campesina, susceptible de movilización general y de formar el séquito aristocrático en algunos casos, no exenta, especialmente en el caso femenino, de la realización de trabajos pesados como muestran los análisis paleopatológi$\cos$.

Se trataba así de una comunidad fuertemente jerarquizada como indican el rico ajuar, por su excepcionalidad, y el estado de los cadáveres de la tumba 7 , junto al repertorio material de la casa en que se sitúa, pero en la que la base aun no había caído en un estado de servidumbre y opresión generalizada. Sin embargo, hay indicios de que esto sí afectaba a parte de la población, probablemente sin ninguna propiedad, obligada, al menos, a enterrarse con sus señores, y constituyendo, junto al ganado apropiado, la base de su poder, de su capacidad de acumulación. Podría ser éste el caso de la tumba 1 en la Terraza Superior en un contexto habitacional importante pero mostrando ajuares pobres y estado físico lamentable. Se daría así una alta tasa de explotación de una pequeña capa de la población lo que se combinaría con la explotación tributaria entre los poblados que perteneciesen a la misma formación social y con la rapiña esporádica sobre otras comunidades.

En la zona más elevada del área excavada (Terraza Superior, Fig. 2), sólo la tumba 2 (Lám. VII), con un hombre adulto y una mujer madura, presenta un ajuar relativamente abundante (un puñal y una lezna de cobre y dos vasos cerámicos) debiendo destacarse la posibilidad de que se tratara en los demás casos de esta zona (tumbas $1,15 \ldots$ ) de siervos o, al menos, capas no guerreras de la población, encargadas de las tareas más duras, tal y como sugiere el análisis paleopatológico.

Como hemos dicho, la tumba 7 (Lám. Vb), situada en la Terraza Media (Fig. 4), durante la fase IIIA, corresponde, sin duda, a los miembros de la clase nobiliaria de Peñalosa, dada la presencia de elementos en plata, los caracteres fisiológicos de los inhumados y sobre todo las características de la tumba en sí, en una habitación creada expresamente para ella en un momento posterior a la primera utilización de la casa VI (Contreras et alii, 1991 y 1993a). Dicha tumba se diferencia tanto de las de la Terraza Superior, en espacios estrechos inutilizados, como de las de la Terraza Inferior en cistas incluidas en bancos que sobresalen del suelo y sobre los que apoyan los recipientes del suelo de ocupación de las casas.

Otro elemento que apoya la división en clases, junto a la referida tumba 7 (Lám. Vb) del poblado y la pérdida de significado relativo de la división sexual, es la presencia junto al individuo femenino de edad adulta de la UH X de un arete de oro, hallazgo excepcional en Peñalosa. La infección que presenta esta mujer, anomalía única en su esqueleto, tal vez fue la que le provocó la muerte.

\section{La relación con la posición en el poblado y en las unidades domésticas}

En la Terraza Inferior de Peñalosa todas las tumbas localizadas con certeza se situaban en la zona oriental (Fig. 3), la más alejada de la entrada y junto al gran muro de fortificación que sirve de límite al poblado al este durante la fase IIIA, aunque antes de afirmar concluyentemente nada debemos tener en cuenta que se trata de la zona mejor conservada de estas casas, tanto por la entidad del muro de cierre como por la dirección de los embites del pantano. En cualquier caso las tumbas en esta zona son todas bancos/cistas realizadas a través de una excavación primaria sobre la roca, después revestida de lajas de pizarra que quedan incluidas en un banco sobre el que se situarían incluso recipientes (Contreras et alii, 1991). Las diferencias entre las tumbas al interior de la misma casa en este área no se pueden analizar dado que en ningún caso hemos localizado dos intactas (a excepción del tratamiento diferencial que reciben los niños de pequeña edad, según se documenta en la casa III), pero las tumbas hasta ahora estudiadas parecen corresponder a los guerreros/campesinos (o sus esposas) del poblado, la base del poder aristocrático.

Las tumbas situadas en la Terraza Media durante la fase IIIA corresponden a los miembros de la clase nobiliaria de Peñalosa, dada la presencia de elementos en plata, los caracteres fisiológicos de los inhumados y sobre todo las características de las tumbas en sí, realizadas ocupando pasillos, habitaciones que quedan inutilizadas o en habitaciones creadas a tal fin (Contreras et alii, 1991, 1993a). En cualquier caso, en muchas de estas tumbas el ajuar y los caracteres físicos de los inhumados revelan el hecho de que en estas casas se inhumaron también siervos que realizaron los trabajos más du- 
ros en favor de los nobles, dándose incluso posibles enterramientos con poca preparación embutidos en los muros como la tumba 3 en el CE Vig.

De todas formas los datos paleopatológicos debemos manejarlos con cuidado, como muestra la tumba 13 (CE Xb) en la que las enfermedades infecciosas pudieron producir la muerte a la mujer adulta que incluía, pero cuya vinculación al poder viene mostrada no sólo por su posición junto a la fortificación (9), sino por la presencia de un anillo de oro en esta tumba.

\section{LAS DIFERENCIAS SOCIALES EN PEÑALOSA. UN AVANCE}

En el registro de Peñalosa los análisis antropológicos han sido fundamentales a la hora de determinar el importante papel de los lazos familiares, dada la asociación de hombres y mujeres en las mismas tumbas y de niños en las cercanías de algunas tumbas de adultos, ya referidos en numerosas publicaciones (Molina et alii, 1975; García Sánchez, 1979). También en este sentido debemos agradecer que los estudios paleopatológicos, en concordancia con otros anteriores para otras zonas del sur de la Península Ibérica (Jiménez y García Sánchez, 1989$90)$, hayan mostrado la importante diferencia-

(9) Hecho presente también por ejemplo en el rico enterramiento infantil de Monachil (Molina, 1983), y en las tumbas "principescas" del área superior de Fuente Alamo (Schubart et alii, 1987a, 1987b, 1993) donde destacan las largas espadas y los brazaletes de oro de las tumbas 1 y 75 , y el ajuar de adornos de la tumba 101. También en Gatas está muy agudizada la diferenciación social destacando especialmente la tumba 2 (Siret y Siret, 1890: 223-224; Chapman et alii, 1987) aun entre las que se han excavado en las campañas recientes (Castro et alii, 1990, 1991; Buikstra et alii, 1991), en las que se han localizado incluso algunos elementos de plata en las tumbas 24 y 29 , que sólo pueden compararse al brazalete de la tumba 8 , aunque es la alta proporción de enterramientos sin ajuar, si bien la mayoría de ellos eran infantiles, lo que más destaca, y en este sentido no podemos olvidar la tumba 26 (Castro et alii, 1991) en la que el esqueleto de una mujer, asociado a un enterramiento infantil, presenta hipoplasia $\mathrm{y}$ artritis (Buikstra et alii, 1991). Tampoco otros enterramientos de adultos en cista, como las tumbas 33 y 35 (Castro et alii, 1993) muestran un ajuar relevante, lo que parece destacar aún más la jerarquización que hemos referido y muestra además diferencias con el uso que en el Bronce Pleno de Fuente Alamo tendrán las cistas como enterramiento de la élite (Schubart et alii, 1987a).

T. P., $52, \mathrm{n}^{\circ} 1,1995$ ción interna en estas comunidades en términos de trabajo realizado y malformaciones consiguientes, hasta tal punto que aquéllos que han trabajado menos tienen asociados los elementos de ajuar más interesantes (aretes de plata p. ej.) y se sitúan en la tumba más espectacular (Contreras et alii, 1991).

En otros casos se ha llegado a probar no sólo la diferencia tipológica entre la cerámica del poblado y la de la necrópolis (Molina et alii, 1975; Contreras, 1986) presente también en Peñalosa (Contreras et alii, 1990) sino incluso la diferencia en manufactura y materias primas empleadas, hasta tal punto que algunos elementos se realizan expresamente para su utilización como ofrendas funerarias, especialmente para la clase alta (Contreras et alii, 1987-88).

Es interesante también la presencia de una estructura sellada con abundantes restos animales en el entorno de la gran tumba ${ }^{\circ} 7$ de mampostería y con rico ajuar. Con el estudio del yacimiento ya muy avanzado y pese a la variedad de especies que incluye podemos concluir que se trata de ofrendas funerarias dado que la limpieza de los pisos de ocupación sugiere que la basura se arrojaría generalmente fuera del poblado. Allí también se desarrollarían las actividades metalúrgicas más contaminantes, documentadas gracias a las estructuras de la primera fase de ocupación (IIIB) selladas por las nuevas terrazas de hábitat que acompañaron la expansión del poblado en la fase IIIA (Contreras et alii, 1991, 1993a). En cualquier caso y pese a las limitaciones de la muestra la clasificación tripolar de la sociedad (nobleza, guerreros/campesinos, siervos), que desarrollaremos en la segunda parte de este trabajo, ayuda a comprender lo fundamental de las asociaciones documentadas en cada vivienda.

Así todos estos elementos, junto con el análisis de las unidades domésticas, permiten discernir la presencia de siervos domésticos, al documentarse enterramientos ricos y pobres en las mismas estructuras de habitación (UH VIII). Esto se aprecia también en Purullena al eliminar de la muestra los enterramientos infantiles sin ajuar o asociarlos al grupo empobrecido (Molina, 1983: 98), siendo muy significativo que numerosas veces cuando los niños presentan ajuar éste es abundante. No hemos documentado la unión de una clientela de guerreros en las mismas casas de los aristócratas pero su presencia en las casas inmediatas, dada la topografía de los 
asentamientos argáricos adquiere un doble sentido descendente y anular con respecto a las élites que pudo, sin embargo, ser más agudo en el caso de Fuente Alamo (Schubart y Arteaga, 1986), y que tiende a reproducir el modelo tumular presente en otras zonas europeas y otros momentos históricos en los que las relaciones sociales estuvieron dirigidas por una clase noble.

Esos siervos (10) pudieron desarrollar labores domésticas y ocuparse de los rebaños mientras los nobles se encargaban de la rapiña y la guerra, organizaban la distribución de los productos y el aprovechamiento de la tierra que en teoría aún no había pasado a propiedad familiar. En cualquier caso la oposición fundamental de clase al interior de esta sociedad se da entre la aristocracia y los siervos, adquiriendo las relaciones sociales entre la aristocracia y la capa de campesinos/guerreros un carácter subordinado que, sin embargo, puede tener un importante papel en la transformación social por la lucha de esta capa por evitar su empobrecimiento y la caída en servidumbre.

\section{BIBLIOGRAFÍA}

Arribas, A. (1973): "Panorama de la Arqueología de la provincia de Jaén". Actas del XII Congreso Nacional de Arqueología (Jaén, 1971): 9-23. Zaragoza.

Arribas. A.; Molina, F.; Carrión. F.; Contreras. F.; Martínez, G.; Ramos, A.; Sáez, L.; Torre. F. de la; BlanCO, I. y MARTINEZ, J. (1987): "Informe preliminar de los resultados obtenidos durante la VI campaña de excavaciones en el poblado de Los Millares (Santa Fe de Mondújar, Almería), 1985". Anuario Arqueológico de Andalucía, 1985, II: 245-262. Junta de Andalucía. Sevilla.

(10) La caracterización como siervo se toma aquí en un sentido restringido para referirnos a las personas directamente dependientes de las familias nobles, pero el término lo podemos emplear también para definir al conjunto de las clases explotadas de la época desde el momento en que la militarización supone un freno a su libertad de desplazamiento y una amenaza sobre su vida y sus posesiones. De igual forma en las sociedades centralizadas anteriores, que consideramos formaciones sociales de tipo "asiático" se puede considerar que todos los campesinos son siervos del Estado. En cualquier caso el sistema no fue tan efectivo como en otras sociedades aristocráticas mucho más recientes, con un excedente enajenable mayor y un mayor desarrollo de las fuerzas productivas que facilitaba no sólo éste sino la capacidad de exacción a través de las armas o la simple exhibición de poder.
Aubet, Ma.E.; SERnA. Ma.R.; EsCACENA, J.L. y Ruiz, M.M. (1983): "La Mesa de Setefilla, Lora del Río (Sevilla). Campaña de 1979". Excavaciones Arqueológicas en España, 122. Ministerio de Cultura. Madrid.

Bass. W.M. (1981): "Human osteology. A laboratory and field manual”. Missouri Archeological Society. Columbia.

Buikstra. J.; Castro, P.V.; Chapman, R.W.; González, P.; Hoshower, L.M.; Lull. V.; Picazo, M.; Risch, R. y Sanahuja, E. (1991): "La necrópolis de Gatas". Anuario Arqueológico de Andalucía, 1990, II: 261-276. Junta de Andalucía. Sevilla.

Cabanas, R. (1953): "La geología de la Provincia de Jaén en relación con las obras hidraúlicas". Boletín del Instituto de Estudios Giennenses, II, 4. Jaén.

Caro, A. (1989): "Consideraciones sobre el Bronce Antiguo y Pleno en el Bajo Guadalquivir". En M ${ }^{\mathrm{a}}$.E. Aubet (coord.): "Tartessos. Arqueología Protohistórica del Bajo Guadalquivir". Sabadell: 85-120.

Carrasco, J. (1979): “Algunas cuestiones acerca de la Cultura argárica en la provincia de Granada". Actas del XV Congreso Nacional de Arqueología (Lugo 1977): $265-$ 277. Zaragoza

Castro, P.; Chapman, R.W.; González. P.; Lull, V.; Picazo, M.; Risch, R. y Sanahuja, Ma.E. (1990): "Proyecto Gatas (Turre, Almería). Tercera Campaña 1987”. Anuario Arqueológico de Andalucía, 1987, II: 225-231. Junta de Andalucía. Sevilla.

- (1991): "Informe preliminar de la tercera campaña de excavaciones en el yacimiento de Gatas (Turre, Almería). Septiembre 1989". Anuario Arqueológico de Andalucía, 1989, II: 219-226. Junta de Andalucía. Sevilla.

Castro, P.; Chapman, R.W.; González, P.; Lull, V.; Mico, R.; Picazo, M.; Risch, R. y Sanahuja, Mª.E. (1993): "Cuarta campaña de excavaciones en el yacimiento de Gatas (Turre, Almería), Septiembre 1991". Anuario Arqueológico de Andalucía, 1991, II: 17-23. Junta de Andalucía. Sevilla.

Chapman, R.W. (1991): "La formación de las sociedades complejas. La Península Ibérica en el marco del Mediterráneo Occidental”. Ed. Crítica. Barcelona.

Chapman, R.W.; Lull, V.; Picazo, M. y Sanahuja, Ma.E. (1987): "Avance de la prospección arqueológica en el yacimiento de Gatas (Turre, Almería). SeptiembreOctubre 1985". Anuario Arqueológico de Andalucía, 1985, II: 33-41. Junta de Andalucía. Sevilla.

Contreras. F. (1986): "Aplicación de métodos y análisis estadísticos a los complejos cerámicos de la Cuesta del Negro (Purullena, Granada)". Tesis Doctorales de la Universidad de Granada. Granada.

- (1995): "Peñalosa. Un Proyecto de Investigación de la edad del Bronce en el Alto Guadalquivir". Actas del $1^{\circ}$ Congreso de Arqueología Peninsular (Porto, 1993), V: 142-157. Oporto.

Contreras, F.; Nocete, F. y Sánchez, M. (1987b): "Primera campaña de excavaciones en el yacimiento de la Edad del Bronce de Peñalosa (Baños de la Encina, Jaén)". Anuario Arqueológico de Andalucía, 1986, II: 342-352. Junta de Andalucía. Sevilla. 
- (1990): "Segunda campaña de excavaciones en el yacimiento de la Edad del Bronce de Peñalosa (Baños de la Encina, Jaén)". Anuario Arqueológico de Andalucía, 1987, II: 252-261. Junta de Andalucía. Sevilla.

Contreras, F.; Capel, J.; Esquivel, J.A.; Molina, F. y TORRE, F. de la (1987-88): "Los ajuares cerámicos de la necrópolis argárica de la Cuesta del Negro (Purullena, Granada). Avance al estudio analítico y estadístico". Cuadernos de Prehistoria de la Universidad de Granada, 12-13: 135-156.

Contreras, F.; Nocete, F.; Sánchez, M.; Lizcano, R.; Pérez, C.; Casas, C.; Moya. S. y Cámara, J.A. (1991): "Tercera campaña de excavaciones en el poblado de la Edad del Bronce de Peñalosa (Baños de la Encina, Jaén)”. Anuario Arqueológico de Andalucía, 1989, II: 227-236. Junta de Andalucía. Sevilla.

Contreras, F.; Cámara, J.A.; Moya, S. y Sánchez, R. (1992): "Primer avance metodológico del estudio de la cultura material del poblado de Peñalosa (Baños de la Encina, Jaén)". Anuario Arqueológico de Andalucía, 1990, II: 281-290. Junta de Andalucía. Sevilla.

Contreras, F.; Nocete, F.; Sánchez, M.; Lizcano, R.; Pérez, C.; Cámara, J.A. y Moya, S. (1993)a: “Análisis histórico de las comunidades de la Edad del Bronce de la Depresión Linares-Bailén y estribaciones meridionales de Sierra Morena". En "Investigaciones Arqueológicas en Andalucía (1985-1992). Proyectos, (Huelva, 1993)". Junta de Andalucía. Huelva: 429-440.

Contreras, F.; Sánchez, M.; Cámara, J.A.; Gómez, E.; Lizcano, R.; Moreno, A.; Moya, S.; Nocete, F.; Pérez, C.; Pregigueiro, R. y Sanchez, R. (1993)b: "Análisis histórico de las comunidades de la Edad del Bronce en la Depresión Linares-Bailén y estribaciones meridionales de Sierra Morena. Actuaciones en 1991". Anuario Arqueológico de Andalucía, 1991, II: 289-294. Junta de Andalucía. Sevilla.

Corchado Soriano, M. (1963): "Pasos naturales y antiguos caminos entre Jaén y La Mancha". Boletín del Instituto de Estudios Giennenses, 38: 9-41.

Delibes, G. y Fernández-Miranda, M. (1986-87): “Aproximación a la cronología del grupo Cogotas I". Zephyrus, XXXIX-XL: 17-30.

Delibes, G.; Fernández-Miranda, M.; Martín, A. y MoliNA, F. (1988): "El Calcolítico de la Península Ibérica". Rassegna di Archeologia, 7: 256-262.

EsparZA, A. (1990): "Sobre el ritual funerario de Cogotas I". Boletín del Seminario de Arte y Arqueología, LVI: 106-143.

Ferembach, D.; Schwidetzky, I. y Stloukal, M. (1979): "Recommandations pour determiner l'age et le sexe sur le squelette". Bulletin et Mémoires de la Société d'Anthropologie de Paris, 6: 7-45.

FINNEGAN M. (1978): "Non-metric variation of the infracranial skeleton". Journal Anatomy, 25: 23-37.

García SÁnCHEZ, M. (1979): "Enterramiento doble en una cista argárica procedente de Puerto Lope (Moclín, Granada)". Cuadernos de Prehistoria de la Universidad de Granada, 4: 227-250.

Goodman A.H.; Thomas, R.B.; Swedlund, A.C. y ArmeLAGOS G.J. (1988): "Biocultural perspectives on stress in prehistoric, historical and contemporary population research". Yearbook Physical Anthropology, 31: 169202.

Hernández Pacheco, E. (1926): "La Sierra Morena y la Llanura Bética". Madrid.

Higueras Arnal, A. (1961): "El Alto Guadalquivir. Estudio geográfico". Instituto de Estudios Giennenses y C.S.I.C. Zaragoza.

Hornos, F.; Nocete, F.; Crespo, J.M.; Zafra, N. y Martínez, P. (1987)a: "Excavación de urgencia en el Cerro del Salto de Miralrío (Vilches, Jaén). 1985". Anuario Arqueológico de Andalucía 1985, III: 192-198. Junta de Andalucía. Sevilla.

Hornos, F.; SÁnchez, M. y LóPEZ, J. (1987)b: "Excavación de urgencia en el sector Saludeja-Redonda de Miradores de la muralla de Ubeda (Jaén). 1985". Anuario Arqueológico de Andalucía, 1985, III: 199-205. Junta de Andalucía. Sevilla.

Jiménez, S.A. y García SÁnchez, M. (1989-90): "Estudio de los restos humanos de la Edad del Bronce del Cerro de la Encina (Monachil, Granada)". Cuadernos de Prehistoria de la Universidad de Granada, 14-15: 157. 180.

Jimeno, A. (1984): Los Tolmos de Caracena (Soria). (Campañas de 1977, 1978 y 1979). Nuevas bases para el estudio de la Edad del Bronce en la zona del Alto Duero. Excavaciones Arqueológicas en España, 134. Ministerio de Cultura. Madrid.

Lizcano, R.; Nocete, F.; Pérez, C.; Contreras, F. y SÁNCHEZ, M. (1990): "Prospección arqueológica sistemática en la cuenca alta del río Rumblar". Anuario Arqueológico de Andalucía, 1987, II: 51-59. Junta de Andalucía. Sevilla.

lizcano, R.; Cámara, J.A.; Riguelme, J.A.; Cañabate. Ma.L.; SÁnChez A. y Afonso, J.A. (e.p.): "El Polideportivo de Martos. Estrategias económicas y símbolos de cohesión en un asentamiento del Neolítico Final del Alto Guadalquivir". Cuadernos de Prehistoria de la Universidad de Granada, 16-17, 1991-92. Granada.

Lizcano, R.; Gómez, E.; Cámara, J.A.; Aguayo, M.; Araque, D.; Bellido, I.; Contreras, L.; Hernández, M.; Izouierdo, M. y Ruiz, J. (1993): "Primera campaña de excavación de urgencia en el Pabellón Polideportivo de Martos (Jaén)". Anuario Arqueológico de Andalucía, 1991, III: 278-291. Junta de Andalucía. Sevilla.

Lovejoy C.O.; MeIndL, R.S.; Pryzbeck, T.K. y Mensforth, R.P. (1985): "Chronological metamorphosis of the auricular surface of the ilium: a new method for the determination of adult skeletal age at death". American Journal of Physical Anthropology, 68: 15-28.

Lull, V. (1983): "La "Cultura" del Argar. Un modelo para el estudio de las formaciones económico-sociales prehistóricas". Ed. Akal. Madrid.

Lull, V. y Estévez, J. (1986): "Propuesta metodológica para el estudio de las necrópolis argáricas". En "Homenaje a Luis Siret (1934-1984)". Junta de Andalucía. Sevilla: $441-452$.

Martín de LA Cruz, J.C. (1989): "El Bronce en el valle medio del Guadalquivir". En $M^{\mathrm{a}}$.E. Aubet (coord.) "Tartessos. Arqueología protohistórica del Bajo Guadalquivir". Sabadell: 121-143. 
Molina, F. (1978): "Definición y sistematización del Bronce Tardío y Final en el Sudeste de la Península Ibérica". Cuadernos de Prehistoria de la Universidad de Granada, 3: 159-232.

- (1983): "La Prehistoria". En F. Molina y J.M. Roldán: "Historia de Granada I. De las primeras culturas al Islam". Ed. Don Quijote. Granada: 11-131.

Molina, F. y PAREJA, E. (1975): "Excavaciones en la Cuesta del Negro (Purullena, Granada). Campaña de 1971". Excavaciones Arqueológicas en España, 86. Ministerio de Cultura. Madrid.

Molina, F.; Carrasco, J. y Torre. F. de la (1975): "Excavaciones en el yacimiento de "La Cuesta del Negro" (Purullena, Granada). I. La necrópolis. Actas ciel XIII Congreso Nacional de Arqueología (Huelva 1973): 387 192. Zaragoza.

Molina, F.; Torre, F. de la; Nájera, T.; Aguayo, P. y SÁEZ, L. (1979): "Excavaciones en Úbeda la Vieja y Cabezuelos (Jaén)". Actas del XV Congreso Nacional de Arqueología (Lugo, 1977): 287-296.. Zaragoza.

Molina, F.; Nájera, T. y Aguayo, P. (1979): "La Motilla del Azuer (Daimiel, Ciudad Real). Campaña de 1979". Cuadernos de Prehistoria de la Universidad de Granada, 4: 265-294.

Molina, F.; Aguayo, P.; Fresneda, E. y Contreras. F. (1986): "Nuevas investigaciones en yacimientos de la Edad del Bronce en Granada". En "Homenaje a Luis Siret (1934-1984)". Junta de Andalucía. Sevilla: 353360.

MORENO, Ma.A. (1993): "El Malagón: un asentamiento de la Edad del Cobre en el Altiplano de Cúllar-Chirivel". Tesis Doctorales de la Universidad de Granada microfilmadas. Granada.

Muñoz Cobos, M. (1976): "Poblado con necrópolis del Bronce II Mediterráneo en Peñalosa, término de Baños de la Encina". Boletín del Instituto de Estudios Giennenses, 90: 45-54

Nájera, T. (1984): "La Edad del Bronce en La Mancha Occidental". Tesis Doctorales de la Universidad de Granada, 458. Granada.

NÁJERA, T. y Molina, F. (1977): "La Edad del Bronce en La Mancha. Excavaciones en las motillas del Azuer y Los Palacios (Campaña de 1974)". Cuadernos de Prehistoria de la Universidad de Granada, 2: 251-300.

NOCETE, F. (1994): "La formación del Estado en las Campiñas del Alto Guadalquivir (3000-1500 a.n.e)". Serie Arte y Arqueología, 23. Universidad de Granada. Granada.

Nocete, F.; Sanchez, M.; Lizcano, R. y Contreras. F. (1987): "Prospección arqueológica sistemática en la cuenca baja/media-alta del río Rumblar (Jaén)”. Anuario Arqueológico de Andalucía, 1986, II: 75-78. Junta de Andalucía. Sevilla.

Nocete, F.; Crespo, J.M. y Zafra, N. (1986): "Cerro del Salto. Historia de una periferia”. Cuadernos de Prehistoria de la Universidad de Granada 11: 171-198.

Olivier, G. (1960): “Pratique anthropologique". Vigot Frères Eds. Paris.

Ortner, D.J. y Putschar, W.G. (1985): "Identification of pathological conditions in human skeletal remains". Smithsonian Institution Press. Washington.
Pérez, C.; Nocete, F.; Moya, S.; Burgos, A. y Barragán, M. (1992)a: "Prospección arqueológica sistemática en la cuenca del río Jándula". Anuario Arqueológico de Andalucía, 1990, II: 99-109. Junta de Andalucía. Sevilla.

Pérez. C.; Lizcano, R.; Moya, S.; Casado, P.; Gómez, E.; Cámara, J.A. y Martínez, J.L. (1992)b: "Segunda campaña de prospecciones arqueológicas sistemáticas en la Depresión Linares-Bailén. Zonas meridional y oriental". Anuario Arqueológico de Andalucía, 1990, II: 86-95. Junta de Andalucía. Sevilla.

Pérez, C.; Casas, C.; Jiménez. G. y Martínez, P. (1992c): "Plaza de Armas de Puente de la Reina. Excavaciones arqueológicas de urgencia. Informe preliminar". Anuario Arqueológico de Andalucía, 1990, III: 284-293. Junta de Andalucía. Sevilla.

Ruiz, A.; Nocete, F. y SÁnchez, M. (1986): "La Edad del Cobre y la argarización en tierras giennenses". En "Homenaje a Luis Siret, (1934-1984)". Junta de Andalucía. Sevilla: 271-286.

Ruz TABOAdA, A. (1993): "Producción y explotación económica en las estribaciones nororientales de los Montes de Toledo durante la Edad del Bronce". Complutum, 4: 311-320.

SChubart. H. y Arteaga, O. (1986): "Fundamentos arqueológicos para el estudio socioeconómico y cultural del área de El Argar". En "Homenaje a Luis Siret (19341984)". Junta de Andalucía. Sevilla: 289-307.

Schubart, H.; Arteaga, O. y Pingel, V. (1987)a: "Fuente Álamo. Informe preliminar sobre la excavación de 1985 en el poblado de la Edad del Bronce". Ampurias, 47: 70-107.

- (1987)b: "Fuente Álamo. Informe preliminar sobre la excavación de 1985 en el poblado de la Edad del Bronce”. Anuario Arqueológico de Andalucía, 1985, II: 305307. Junta de Andalucía. Sevilla.

Schubart, H.; Pingel. V. y Arteaga, O. (1993): "Fuente Alamo. Informe preliminar sobre la excavación realizada en 1991 en el poblado de la Edad del Bronce". Anuario Arqueológico de Andalucía, 1991, II: 24-27. Junta de Andalucía. Sevilla.

Shennan. S. (1982): "Ideology, change and the European Bronze Age". En I. Hodder (ed): "Symbolic and structural archaeology". Methuen Ed. Cambridge: 155-161.

SIRET, L. y SIRET. H. (1890): "Las primeras edades del metal en el Sudeste de España. Resultados obtenidos en las excavaciones hechas por los autores de 1881 a 1887". Barcelona.

TORrE, F. de la (1978): "Estudio de las secuencias estratigráficas de la Cultura del Argar en la provincia de Granada". Cuadernos de Prehistoria de la Universidad de Granada, 3: 143-158.

Trancho G.J.; Botella M.C. y Hernández M. (e.p.): “Cribra orbitalia: incidencia y distribución en diferentes poblaciones de la Península Ibérica”. En M. Botella, P. Souich y S. Jiménez (eds): "Nuevas perspectivas en Antropología". Granada.

VALIENTE, J. (1980): "La expansión argárica en la Alta Andalucía”. Caesaraugusta, 51-52: 87-102.

WALKer, P.L. y Hollimon, S.E. (1989): "Changes in osteoarthritis associated with the development of a maritime 
economy among southern California Indians". International Journal of Anthropology, 4, 3: 171-183.

Woods, J.W.; MiLner, G.J.; Harpending, H.C. y Weiss, K.M. (1992): "The osteological paradox: Problems of inferring prehistoric health from skeletal samples". Current Anthropology, 33, 4: 343-370.

ZAFRA, N. (1991): "Excavaciones arqueológicas en el Cerro del Alcázar (Baeza, Jaén). Campaña de 1989. Informe previo". Anuario Arqueológico de Andalucía, 1989, III: 328-337.

ZAFrA, N. y PÉrEZ, C. (1992): "Excavaciones arqueológicas en el Cerro del Alcázar de Baeza. Campaña de 1990. Informe preliminar". Anuario Arqueológico de Andalucía, 1990, III: 294-303.

T. P., 52, n. ${ }^{\circ} 1,1995$ 